\title{
Estimating, and setting targets for, the resilience of transport infrastructure
}

Bryan T. Adey PhD

Professor, Head of the Infrastructure Management Group, Institute of

Construction and Infrastructure Management, ETH Zurich, Zurich, Switzerland (Orcid:0000-0002-4932-5901)

\section{Claudio Martani PhD}

Research Associate, Infrastructure Management Group, Institute of Construction and Infrastructure Management, ETH Zurich, Zurich, Switzerland (Orcid:0000-0002-9039-0908) (corresponding author: martani@ibi.baug.ethz.ch)

\section{Clemens Kielhauser PhD}

Senior Researcher, Centre of Competence for Transport Infrastructure, Berne University of Applied Sciences, Berne, Switzerland (Orcid:0000-0003-1385-9909)

Ignacio Urqulijo Robles MSc Eng

Consultant in Planning \& Environment, WSP Spain, Santander, Spain

(Orcid:0000-0001-6477-2147)
Natalia Papathanasiou PhD, Dipl.-Ing, MSC

Project Engineer, Institute of Construction and Infrastructure Management, ETH Zurich, Zurich, Switzerland (Orcid:0000-0001-7781-051X)

Marcel Burkhalter MSC, ETH CEng

Research Assistant, Institute of Construction and Infrastructure Management, ETH Zurich, Zurich, Switzerland (Orcid:0000-0003-3017-1751)

Iñaki Beltran-Hernando MSc Eng

Project Manager, Tecnalia, Basque Research and Technology Alliance, Derio, Spain

David Garcia-Sanchez PhD, MSc Eng

Knowledge Leader, Tecnalia, Basque Research and Technology Alliance, Derio, Spain (Orcid:0000-0002-4763-206X)

To ensure that transport infrastructure provides acceptable levels of service with respect to extreme events, the resilience of the infrastructure needs to be estimated and targets for it need to be set. In this paper, the methodology proposed in the Foresee EU research project is presented. The methodology allows managers to measure, and set targets for, the resilience of transport systems in all situations. It requires clear definition of the transport system and how the service provided and the resilience are to be measured. The methodology allows consideration of the fact that transport infrastructure managers need to estimate resilience with various degrees of accuracy depending on the specific problem to be addressed, the time frame at disposition and the expertise available. These various levels of accuracy are covered by proposing the use of (a) simulations, (b) indicators whose values are directly related to increases in expected restoration intervention costs and reductions in service, and (c) the percentage of fulfilment of indicators. Once resilience has been estimated, the methodology provides guidance on how to set resilience targets with or without cost-benefit analysis. For demonstration, the explanation of the steps of the guideline is supported by their use for a simple transport system.

\section{Introduction}

The functioning of society depends on the transportation of goods and persons. The infrastructure required to enable transportation is built to ensure that this can happen in specified ways - that is, built to provide specified levels of service. As losses in service due to disruptive events (e.g. natural hazards such as floods, earthquakes and heavy snowfalls) can have significant societal consequences, the transport infrastructure should be managed in such a way that the consequences of extreme events are minimised. To do so, it is necessary for transport infrastructure managers to, $(a)$ on one hand, have a clear idea of the service that the infrastructure is providing and an understanding of its resilience, if it is affected by natural hazards, and, $(b)$ on the other hand, to understand how the resilience of a network can be modified to counteract the loss of service following a hazard and to provide specified levels of service during and following the occurrence of extreme events - that is, to set resilience targets.

A solid and consistent methodology does not exist yet to measure (i.e. to assess the importance, effect or value of (something)) the resilience of transport infrastructure (Transport infrastructure is considered to be all infrastructure for enabling travel, e.g. road infrastructure and rail infrastructure or combinations of both.) with respect to a defined service or set of services and set targets of resilience. This is largely due to a lack of a commonly agreed, widespread consideration of what the service and resilience of an infrastructure are and how these are to be quantified.

In this paper, a guideline is presented that allows managers to measure the service and the resilience, based on the publication by Adey et al. (2019), and set resilience targets, based on the publication by Kielhauser et al. (2019), for transport infrastructure networks. For the measure of the service provided by, and the resilience of, transport infrastructure, the following definitions of service and resilience are considered. In this paper, service is defined as the ability to perform an activity in a certain way. Although the service to be provided by transport infrastructure is, in general, the safe and sustainable mobility of persons and goods, more exact definitions are required to estimate resilience rigorously and set targets. A more exact definition is, for example, that the service of a road is the ability to transport goods and persons from A to B, within a specific amount of time and for goods without being damaged, while for persons without being hurt or losing their lives. Once it is determined how service is to be measured, the loss of service due to the occurrence of natural hazards, and by reverse the resilience, can be measured as the ability to continue to provide service if a hazard event occurs. Resilience, with this definition, is to be measured, using each measure of service 
deemed relevant, to assess how service is being affected, and the cost of the interventions required to ensure that the infrastructure once again provides an adequate service. When considering natural hazards, resilience is therefore measured as the difference between $(a)$ the service provided by the infrastructure if no hazard event occurs and the service provided by the infrastructure if a hazard event occurs and $(b)$ the costs of intervention if no hazard event occurs and the costs of interventions if a hazard event occurs. To clarify this definition, in Figure 1 resilience is shown for two measures of service as the area between the red-blue and green lines - the larger the area, the less resilient the infrastructure. In Figure 1(a), the resilience is shown using the measure of service 'expected cumulative yearly travel time of goods and persons being transported from A to B'. The green line indicates the amount of travel time expected if there are no hazard events. The red line indicates how the travel time is expected to increase from the moment a specific hazard event begins to the moment that the hazard event ends. The blue line indicates how travel time is expected to decrease from the moment the hazard event ends, until the moment that the cumulative yearly travel time of goods and persons travelling from $\mathrm{A}$ to $\mathrm{B}$ is as would be expected without the occurrence of the hazard events - that is, service is restored.

In this paper, a target is defined as a level of service or resilience that stakeholders consider acceptable and for which they are

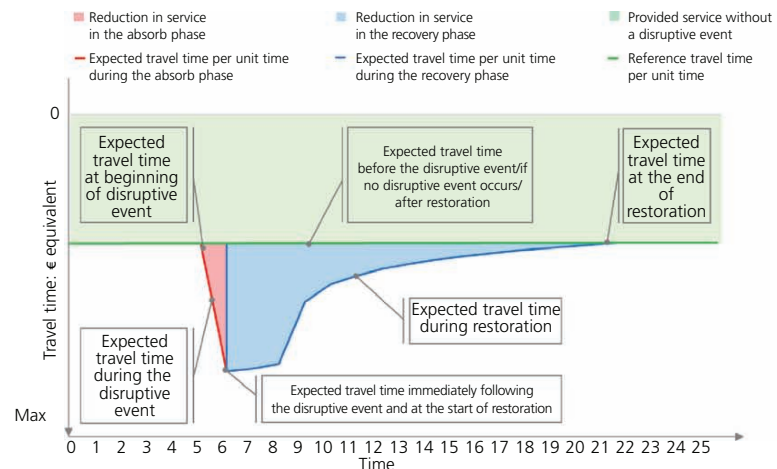

(a)

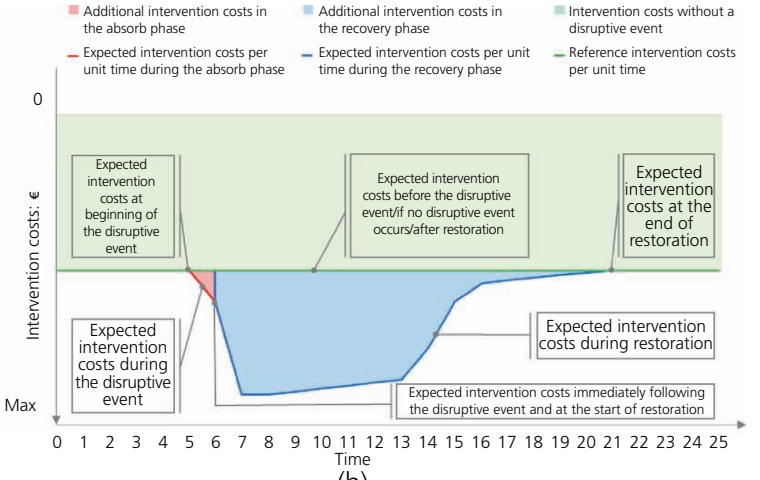

(b)

Figure 1. Illustration of resilience, using the measure of two services, the yearly travel time (a) and the intervention costs (b), on an infrastructure enabling the transport of goods and persons from A to B for a scenario, where a single hazard event occurs and the infrastructure is restored so that it provides that same level of service as it did before the hazard event

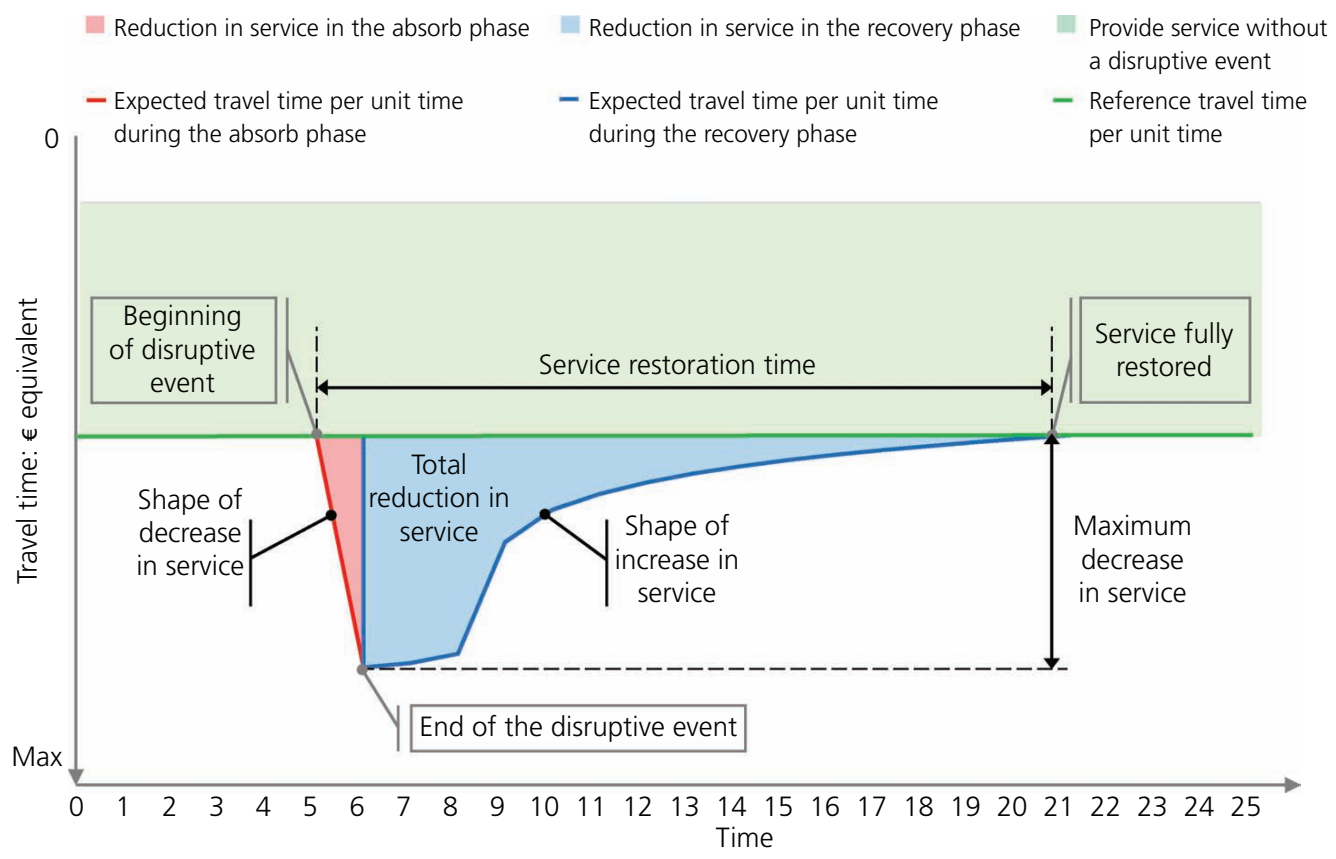

Figure 2. Illustration of resilience using the measure of service travel time, as in Figure 1, showing the various types of targets - that is, maximum decrease in service, shape of decrease in service, shape of service curve during restoration, service restoration time and total reduction in service 
willing to take due actions. The different types of resilience targets are shown in Figure 2.

The remainder of this paper includes an overview of the state of the art and a guideline on how to measure quantitatively, and set targets for, the service and resilience of transport infrastructures. The guideline is to be used by managers to establish how to quantify both the service provided by and the resilience of multimodal transport infrastructure, particularly when the desire is to have estimates that can be used for the determination of the optimal resilience-enhancing interventions to be executed and set resilience targets.

\section{Background}

Recent work on measuring and setting targets for the service provided by, and the resilience of, transport infrastructure is summarised in this section. As efforts increase to improve decision making with respect to the management of infrastructure, researchers and developers of management systems have been working towards quantifying the service provided by the infrastructure so that they can determine the optimal conditions (e.g. time) to execute interventions and making trade-offs between the impacts of executing interventions and the impacts of not executing interventions. Some examples of this work for roads and rail are shown in Table 1.

As there are an increasing number of efforts to measure service, there are also an increasing number of efforts to measure the amount of service lost due to the occurrence of extreme events. Examples of recent work are given in Table 2 that, along with several EU projects that have run on the topic in the last 20 years (e.g. Infrarisk, EU-Circle, Destination Rail, Smart Resilience

Table 1. Examples of work on the measurement of transport service

\begin{tabular}{|c|c|c|}
\hline Citation & Focus of work & Infrastructure \\
\hline Achtnicht (2012) & The quantification of the value of carbon dioxide $\left(\mathrm{CO}_{2}\right)$ & Road \\
\hline Adey et al. (2010) & $\begin{array}{l}\text { An illustration of how the service provided by roads changes as a } \\
\text { function of the physical state of the roads }\end{array}$ & Road \\
\hline Adey et al. (2012) & A complete description of the service provided by roads & Road \\
\hline Adey et al. (2020) & Defining road service & Road \\
\hline Asam et al. (2015) & An adaptation guide for roads due to climate change & Road \\
\hline Caliendo and De Guglielmo (2012) & The quantification of the social cost of accidents & Road \\
\hline de Blaeij et al. (2003) & The quantification of the value of a statistical life & Road \\
\hline Dykes (2018) & The quantification of noise levels within cars & Road \\
\hline Ecoplan (2010) & $\begin{array}{l}\text { A set of indicators for measuring the impacts of road } \\
\text { infrastructure projects }\end{array}$ & Road \\
\hline Elvik (2000) & The cost of road accidents & Road \\
\hline Federal Highway Administration (FHWA, 2002) & Quantifying service to enable the management of bridges & Road \\
\hline Ihs (2004) & The relationship between comfort and road condition & Road \\
\hline Kasnatscheew et al. (2016) & Overview of accident cost calculation methods & Road \\
\hline Korzhenevych et al. (2014) & The quantification of the external costs of road transport & Road \\
\hline Kumares and Samuel (2007) & Principles of evaluating road projects & Road \\
\hline New Zealand Transport Agency (NZTA, 2010) & A guideline to enable the evaluation of road infrastructure projects & Road \\
\hline $\begin{array}{l}\text { Organisation for Economic Co-operation and } \\
\text { Development (OECD, 2018) }\end{array}$ & Strategies and performance indicators to be used in a road section & Road \\
\hline $\begin{array}{l}\text { Schweizerischer Verband der Strassen- und } \\
\text { Verkehrsfachleute (VSS, 2009a, 2009b, 2013) }\end{array}$ & $\begin{array}{l}\text { The quantification of the value of travel time, external costs of } \\
\text { road transport and accident costs }\end{array}$ & Road \\
\hline Wüthrich et al. (2017) & The quantification of the costs of air pollution & Road \\
\hline Aydin (2017) & Service quality evaluation of rail transit systems & Rail \\
\hline Bickel and Friedrich (2005) & Quantification of energy costs & Rail \\
\hline Caetano and Teixeira (2013) & Using availability to plan railway interventions & Rail \\
\hline Cascetta et al. (2011) & Impacts of high-speed rail & Rail \\
\hline Cavana et al. (2007) & Measuring the quality of passenger service & Rail \\
\hline Chou et al. (2014) & $\begin{array}{l}\text { Effects of service quality and customer satisfaction on customer } \\
\text { loyalty in high-speed rail services }\end{array}$ & Rail \\
\hline de Oña et al. (2015) & Perceptions of rail service quality & Rail \\
\hline Eboli and Mazzulla (2012) & Perceptions of railway service & Rail \\
\hline $\begin{array}{l}\text { International Organization for Standardization } \\
(\mathrm{ISO}, 2018)\end{array}$ & $\begin{array}{l}\text { Proposals of indicators and associated test methods have been } \\
\text { developed }\end{array}$ & Rail \\
\hline Jou et al. (2013) & Willingness to pay for comfort on high-speed rail lines & Rail \\
\hline Maibach et al. (2008) & External costs of the transport sector & Rail \\
\hline Milligan et al. (2014) & Value of a statistical life & Rail \\
\hline Nathanail (2008) & Measuring the quality of service for passengers & Rail \\
\hline OECD (2018) & Indicators of the quality of passenger service & Rail \\
\hline Papathanasiou et al. (2020) & Quantifying railway service to plan infrastructure interventions & Rail \\
\hline Stenström et al. (2016) & Availability of rail infrastructure & Rail \\
\hline van Oort and van Nes (2010) & Impact of rail terminal design on transit service reliability & Rail \\
\hline Zalbide et al. (2018) & Risk-based approaches for transport infrastructures & ad/air// \\
\hline
\end{tabular}


Table 2. Examples of work on the resilience of infrastructure

\begin{tabular}{|c|c|}
\hline Citation & Focus of work \\
\hline Adey et al. (2016) & $\begin{array}{l}\text { 'Ensuring acceptable levels of infrastructure-related risks due to natural hazards with emphasis on stress tests'. } \\
\text { This work gives a guideline of how to establish simulations frameworks for the evaluation of resilience. }\end{array}$ \\
\hline Brown et al. (2014) & $\begin{array}{l}\text { Review of resilience of transport networks. This work summarises the problems that transport networks in } \\
\text { the UK are having due to natural hazards and makes recommendations of how to deal with them. }\end{array}$ \\
\hline Figueiredo et al. (2018) & $\begin{array}{l}\text { An approach to strengthen and monitor urban resilience. This work proposes indicators to be used to } \\
\text { monitor the progress of urban areas in becoming more resilient. }\end{array}$ \\
\hline Hackl et al. (2018a) & $\begin{array}{l}\text { Determination of near-optimal restoration programmes for transportation networks following natural } \\
\text { hazard events. This work focuses on explicitly modelling the reconstruction of transportation networks } \\
\text { following a natural hazard. }\end{array}$ \\
\hline Hackl et al. (2018b) & $\begin{array}{l}\text { 'Estimating network related risks: a methodology and an application for roads'. This work includes a detailed } \\
\text { simulation-based risk assessment for a road network in the region of Chur, Switzerland, from the simulation } \\
\text { of rainfall patterns to the quantification of lost service through the entire restoration period. }\end{array}$ \\
\hline Hughes and Healy (2014) & $\begin{array}{l}\text { Measuring the Resilience of Transport Infrastructure. This work proposes a resilience measurement } \\
\text { framework that broadly covers both the technical and organisational dimensions of resilience and breaks } \\
\text { these down into specific principles and measures, which can be utilised to assess resilience qualitatively. }\end{array}$ \\
\hline Jha et al. (2013) & $\begin{array}{l}\text { Building Urban Resilience: Principles, Tools and Practice. This work summarises guiding principles, tools, } \\
\text { and practices in key economic sectors that can facilitate incorporation of resilience concepts into the } \\
\text { decisions about infrastructure managers. }\end{array}$ \\
\hline Lam et al. (2018) & $\begin{array}{l}\text { 'Stress tests for a road network using fragility functions and functional capacity loss functions'. This work } \\
\text { focuses on establishing steps to be used when running simulations to verify the resilience of transport } \\
\text { infrastructure networks. }\end{array}$ \\
\hline Neetesh et al. (2018) & $\begin{array}{l}\text { A mathematical approach to the measurement of resilience. This work proposes resilience metrics to } \\
\text { describe the recovery curve. }\end{array}$ \\
\hline Prior (2015) & $\begin{array}{l}\text { Indicators of resilience for critical infrastructure. This work includes suggestions as to possible indicators of } \\
\text { the resilience of critical infrastructures. }\end{array}$ \\
\hline $\begin{array}{l}\text { Theocharidou and Giannopoulos } \\
\text { (2015) }\end{array}$ & $\begin{array}{l}\text { Critical infrastructure protection. This work describes a risk assessment methodology for critical } \\
\text { infrastructures, presenting an overview of risks. }\end{array}$ \\
\hline $\begin{array}{l}\text { US Department of Transportation } \\
\text { (USDOT, 2015) }\end{array}$ & $\begin{array}{l}\text { Vulnerability assessment. This work describes the functioning of an Excel tool developed to assess } \\
\text { infrastructure vulnerability. }\end{array}$ \\
\hline
\end{tabular}

Indicators for Smart Critical Infrastructure, Resilience Management Guidelines for Critical Infrastructures and Ragtime) set the current state of the art in the EU.

The literature for the general process of setting targets is scarce. While in many of the literature sources concerning service and resilience-specific indicator performance goals, targets or others are mentioned, the way of setting actual values for those targets is not shown. Nevertheless, as setting targets is a well-known part of the general decision-making process, high-level concepts can be found in the appropriate literature - for example, in classic decision-making literature such as Decisions with Multiple Objectives (Keeney and Raiffa, 1993) or Cost-Benefit Analysis (Layard, 1994) and Cost-Benefit Analysis and the Environment (Pearce et al., 2006). Although there is no general method of coming up with actual target values, the literature has collected target values for specific parts of transport systems. For example, Stipanovic et al. (2017) provide an overview of existing performance goals for bridge structures. Tingvall et al. (2010) investigate safety targets that have been set for a road transport system, and Patra et al. (2010) investigate availability targets for railway infrastructure. All these actual targets are, however, tailored to the specific problem investigated with a specific transport system (or part thereof) in mind and should therefore only serve as a starting point when developing own targets.
In summary, there has been considerable work done in the areas of the measurement of service and resilience of transport infrastructure, and some work has been done on setting targets for specific parts of transport infrastructure. An explicit quantitative connection between the service provided by the infrastructure and the resilience of infrastructure and a consistent process for rigorously defining targets for service and the resilience of infrastructure, have, however, been missing until now. The guideline proposed in this paper provides this connection, taking into consideration the results of the works listed in this section.

\section{Guideline}

In this section, the guideline is presented to determine how to measure and set the targets for the service provided by, and the resilience of, transport infrastructure. This involves the execution of the four consecutive actions described in Table 3.

In the next subsections, a detailed description is reported on how to perform all four of the actions required to measure and set the targets for the service and the resilience of transport infrastructure.

\section{Define the transportation system}

Before the service provided by, and the resilience of, transport infrastructure are measured, it is necessary to define the parts of the transport system to be considered (Table 4). It is noted that the 
Table 3. Guideline to measure the service and the resilience of transport infrastructure

\begin{tabular}{|c|c|}
\hline Step & Description \\
\hline $\begin{array}{l}\text { Define the transportation } \\
\text { system }\end{array}$ & $\begin{array}{l}\text { The measure of service and resilience requires taking into consideration many characteristics of the transport } \\
\text { system, including characteristics of } \\
\text { the infrastructure - for example, the number and width of the lanes of a highway and the gradient and } \\
\text { degree of curvature of a railway line } \\
\text { the environment - for example, the number and type of vehicles that are to use a highway and the number } \\
\text { and type of trains to use a railway line } \\
\text { the organisation - for example, how often routine maintenance interventions are executed and what } \\
\text { precautions are made to limit the traffic disruptions to vehicles on roads or trains on railways. } \\
\text { The exact characteristics to be taken into consideration depend on the specific transport system to be analysed. }\end{array}$ \\
\hline Measure the service & $\begin{array}{l}\text { Once the transport system is defined, the service can be measured. Measuring the service provided by transport } \\
\text { infrastructure over time requires modelling } \\
\text { how the service required from the infrastructure is expected to change in the future } \\
\text { how the infrastructure is likely to change in the future. }\end{array}$ \\
\hline Measure the resilience & $\begin{array}{l}\text { Measuring the resilience of infrastructure requires measuring the difference between the service provided over time, } \\
\text { when no hazard event occurs, and when a hazard event occurs. Measuring resilience is more difficult than measuring } \\
\text { service, as it requires estimating what will happen from the point in time that a hazard occurs to the point in time } \\
\text { that the required service is once again provided. This depends, on a first level, on many different factors, including } \\
\text { the probabilities of hazard events occurring } \\
\text { how the infrastructure withstands hazard events } \\
\text { how service is provided when the infrastructure does not work } \\
\text { how the infrastructure is restored following the hazard event } \\
\text { how much it costs to restore the infrastructure.These first-level factors, in turn, depend on many other } \\
\text { factors, such as how well an infrastructure manager (a) is prepared for hazard events, (b) reacts during } \\
\text { hazard event and (c) responds following the hazard event. Moreover, these factors, in turn, depend on more } \\
\text { in-depth factors, such as how an infrastructure manager (a) deals with information - for example, a central } \\
\text { database against many different databases; (b) is structured - for example, by region or by specialisation; and } \\
\text { (c) makes decisions - for example, centralised against decentralised decision making. Due to this complexity, } \\
\text { measuring the resilience of transport infrastructure in detail might not be worthwhile - that is, the gain in } \\
\text { information may not be worth the effort. Instead, it might be worthwhile to use resilience indicators - that is, } \\
\text { indicators of how service will be affected due to a hazard event. The indicator set used will need to capture } \\
\text { adequately the performance of all relevant aspects of the transport system. }\end{array}$ \\
\hline $\begin{array}{l}\text { Set the service and } \\
\text { resilience targets }\end{array}$ & $\begin{array}{l}\text { Setting targets of service and resilience requires that all relevant stakeholders involved with the decisions on the } \\
\text { service and resilience to be provided determine }(a) \text { the boundaries of the decisions - that is, the legal and } \\
\text { stakeholders' requirements; }(b) \text { agree on the method for defining the targets - depending on whether service } \\
\text { and resilience is measured directly or with indicators and whether or not cost-benefit analysis should be used; } \\
\text { and (c) use the method agreed on to define the service and resilience targets. Targets can be set for } \\
\text { either intervention costs or a measure of service. For example, one can concentrate only on the travel time } \\
\text { measure of service and set a target for the maximum decrease following the beginning of the hazard event } \\
\text { and the time until vehicles can once again travel as they could before the event. } \\
\text { combinations of intervention costs and measures of service. For example, one can consider intervention costs } \\
\text { and the travel time measure of service and set a target for the total intervention and travel time costs } \\
\text { following the beginning of the hazard event. } \\
\text { multiple hazards. For example, one can set the maximum additional travel time per week following the } \\
\text { beginning of either a 500-year earthquake hazard event or a 500-year flood event. }\end{array}$ \\
\hline
\end{tabular}

classification of items within a transport system is situation dependent - that is, something that is considered to be in one category for one transport system may be in another category in another transport system. For example, if a bridge is controlled by the responsible organisation, it may be considered to belong to the infrastructure part of the transport system. If a bridge is not controlled by the responsible organisation, it may be considered to belong to the environment.

\section{Measure service}

Within the boundaries of the transportation system defined as in the section headed 'Define the transportation system', the service can be measured as described in Table 5 .

\section{Measure resilience}

The steps to determine how to measure the resilience of transport infrastructure, assuming that the transport system to be considered is defined (as in the section headed 'Define the transportation system') and the service is measured (as in the section headed 'Measure service'), are given in Figures 3-5 and described in the following text.

\section{Step 1: identify the parts of the transport system that are likely to have an effect on resilience following a specific hazard}

The first step is to determine the parts of the transport system that are relevant to the resilience of the infrastructure and the relevant 
Table 4. Parts of the transport system

\begin{tabular}{|c|c|c|c|}
\hline Part & Description & Examples & Control \\
\hline Infrastructure & $\begin{array}{l}\text { The physical assets that are required to provide } \\
\text { service and are considered }\end{array}$ & $\begin{array}{l}\text { Bridges, tunnels, road sections and rail sections that } \\
\text { comprise the infrastructure required for usual and } \\
\text { alternative transport routes }\end{array}$ & $\begin{array}{l}\text { Within the control } \\
\text { of the responsible } \\
\text { organisation }\end{array}$ \\
\hline \multirow[t]{2}{*}{ Environment } & $\begin{array}{l}\text { The physical environment in which the } \\
\text { infrastructure is embedded that might affect the } \\
\text { provision of service }\end{array}$ & $\begin{array}{l}\text { The occurrence of earthquakes and floods, the } \\
\text { proximity of infrastructure to areas where landslides } \\
\text { or avalanches might occur, the traffic volume of } \\
\text { people/goods that demands to be transported from } \\
\text { A to B and the conditions under which it happens }\end{array}$ & $\begin{array}{l}\text { Outside the } \\
\text { control of the } \\
\text { responsible } \\
\text { organisation }\end{array}$ \\
\hline & $\begin{array}{l}\text { The organisational environment in which the } \\
\text { infrastructure management organisation is } \\
\text { embedded that might affect the provision of } \\
\text { service }\end{array}$ & $\begin{array}{l}\text { The regulatory framework, the budget allocated to } \\
\text { the infrastructure management organisation }\end{array}$ & $\begin{array}{l}\text { Outside the } \\
\text { control of the } \\
\text { responsible } \\
\text { organisation }\end{array}$ \\
\hline Organisation & $\begin{array}{l}\text { The organisation(s) responsible for ensuring that the } \\
\text { infrastructure provides service }\end{array}$ & $\begin{array}{l}\text { The organisation(s) or part(s) of the organisation(s) } \\
\text { that monitors the service being provided by the } \\
\text { infrastructure and restores the damaged } \\
\text { infrastructure during extreme event events }\end{array}$ & $\begin{array}{l}\text { Within the control } \\
\text { of the responsible } \\
\text { organisation }\end{array}$ \\
\hline
\end{tabular}

factors. For example, the resilience of infrastructure connecting A to B may be affected by

- the infrastructure, where two of the relevant factors might be how a bridge is designed to resist earthquakes and the condition of the bridge v the environment, where three of the relevant factors might be the likelihood of having a specific magnitude of earthquake; the demand for the transport system to work before, during and after the event; and the suitability of the regulatory framework enabling the expedition of restoration interventions to be executed

Table 5. Steps to measure the service

\begin{tabular}{|c|c|c|}
\hline Step & Name & Description \\
\hline 1 & Define the service & $\begin{array}{l}\text { In defining service, it is helpful to first think of }(a) \text { the relevant stakeholders - that is, the persons and } \\
\text { organisations who are affected by the infrastructure that are to be included in the investigation, and then } \\
\text { (b) the impact of the infrastructure on the stakeholders - that is, how they are affected. }\end{array}$ \\
\hline 2 & $\begin{array}{c}\text { Determine how to } \\
\text { measure service }\end{array}$ & $\begin{array}{l}\text { How the service is to be measured should be stated, including the measures to be used and whether their } \\
\text { values will be determined through simulations or the use of indicators. If indicators are to be used, it should } \\
\text { be stated which indicators are to be used and the frequency with which the values of the indicators will be } \\
\text { collected. If, for example, transport infrastructure exists to enable that persons can be transported from A } \\
\text { to B in } 1 \mathrm{~h} \text { every day for } 365 \text { days, one can define the service provided by the infrastructure in terms of } \\
\text { travel time or travel time costs. If the measure of service is to be travel time, then the amount of travel time } \\
\text { incurred over the course of a year could be estimated } \\
\text { through running simulations of the transportation of persons over the infrastructure over the course of a } \\
\text { year and summing the total amount of travel time, or } \\
\text { by measuring the travel time on specific parts of the infrastructure on } 31 \text { March, } 30 \text { June, } 30 \text { September } \\
\text { and } 31 \text { December and extrapolating this information to cover all parts of the infrastructure and all } \\
\text { periods of time in the year. } \\
\text { Measures of service should be evaluated either } \\
\text { considering the demand and using the expected use of the infrastructure - for example, it is expected } \\
\text { that ten persons are to be transported from A to B in the course of a year and that it will take on } \\
\text { average } 1 \mathrm{~h} \text { to transport each of them, yielding a measure of service of } 10 \mathrm{~h} \text {, or } \\
\text { considering the capacity, by using the expected ability to transport persons - for example, if ten persons } \\
\text { wanted to travel from A to B in the course of the year, it would take on average } 1 \mathrm{~h} \text { to transport each of } \\
\text { them, yielding a measure of service of } 10 \mathrm{~h} \text {. } \\
\text { The first way takes into consideration the expected demand; the second does not. }\end{array}$ \\
\hline 3 & Measure the service & $\begin{array}{l}\text { Once it is determined how to measure service, it needs to be done, either using the results of simulations or using } \\
\text { indicators. The result in both cases, however, is the measure of service, where the measure of each service is } \\
\text { expressed in a normalised units (e.g. in monetary values). For example, if it is expected that ten persons are to be } \\
\text { transported from A to B every day over the course of a year, the service provided by the infrastructure is } \\
\text { measured as } 3650 \mathrm{~h}(10 \times 1 \times 365) \text {. If travel time has a value of } € 10 \text {, the service provided is measured as } \\
€ 36500 \text {. It is to be noticed that these measures of service are solely to be used as reference values in measuring } \\
\text { resilience. They are not measurements of the value of the service provided by the transport system, which would } \\
\text { require a consideration of how an area would function with and without the transport system. The models } \\
\text { required to measure service depend greatly on the level of detail desired. }\end{array}$ \\
\hline
\end{tabular}




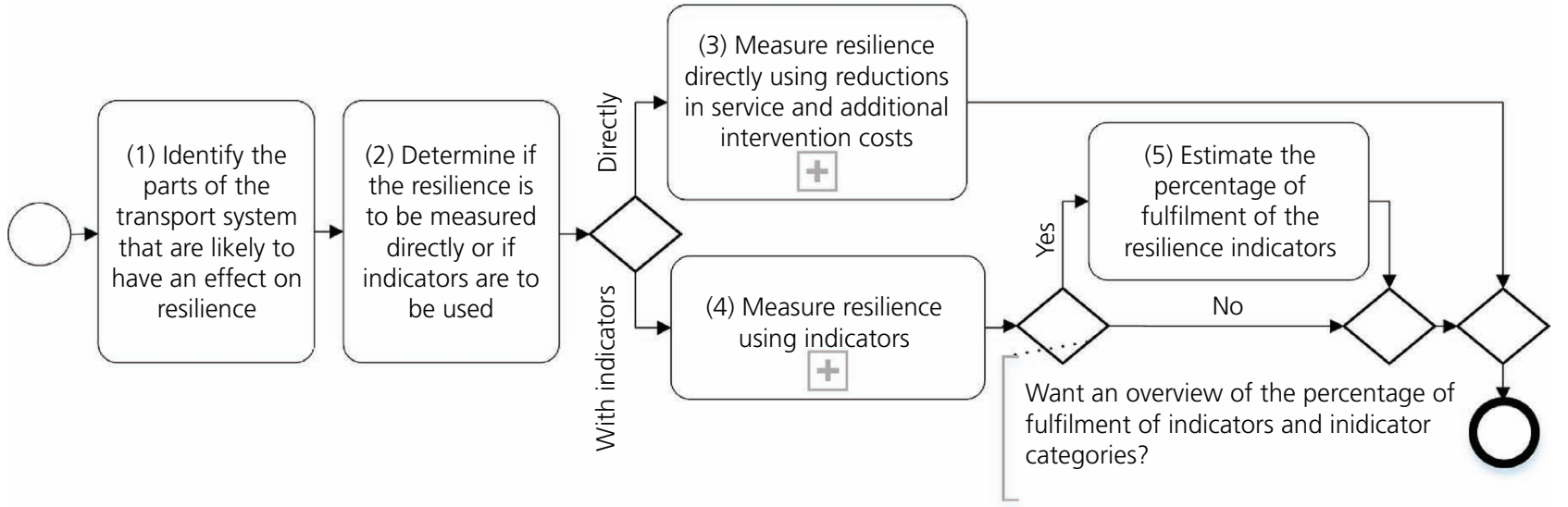

Figure 3. Steps to measure the resilience

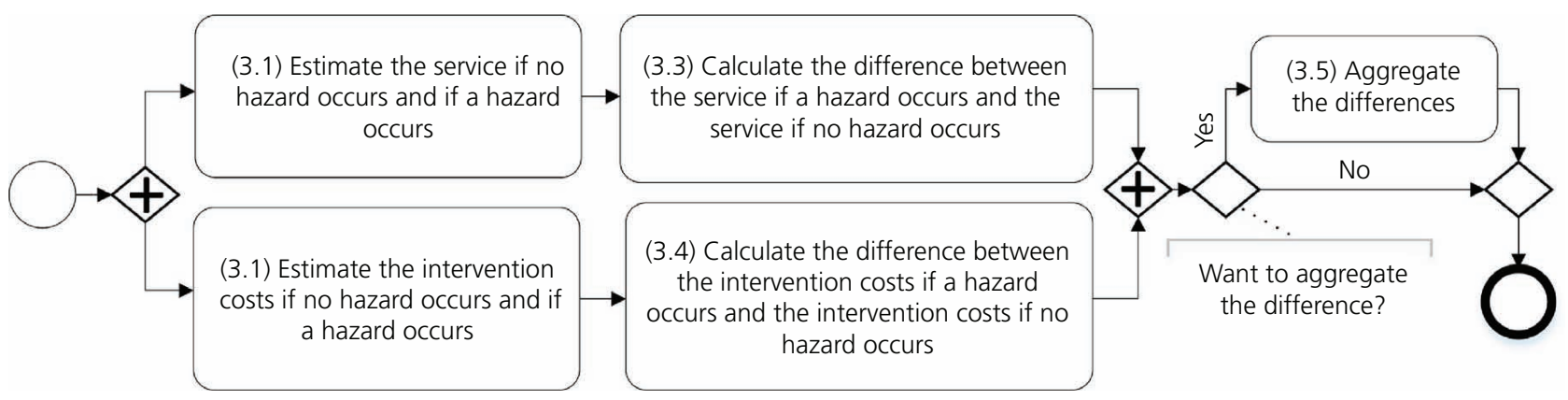

Figure 4. Steps to measure the resilience directly (step 3 in Figure 3)

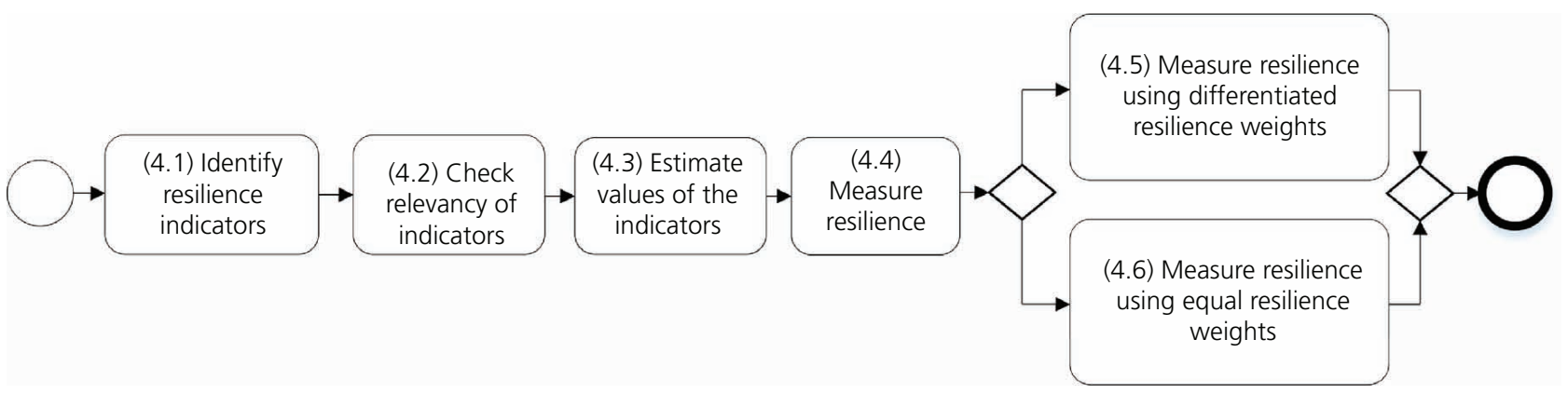

Figure 5. Steps to measure the resilience using indicators (step 4 in Figure 3)

- the organisation, where two of the relevant factors might be the existence of regular monitoring plans and the existence of plans to restore the infrastructure following an earthquake.

Step 2: determine if the resilience is to be measured directly or if indicators are to be used

The second step is to decide if resilience is to be measured

- directly using the reductions in service and additional intervention costs if a hazard occurs
- indirectly using weighted indicators

- indirectly using unweighted indicators.

If resilience is to be measured directly using reductions in service, the provided service needs to be simulated first without the hazard event and then with all hazard events to be used to measure resilience. If it is not desired to measure resilience directly using the reductions in service - for example, due to lack of time, lack of money or lack of modelling expertise - indicators can be used. 


\section{Step 3: measure resilience directly using reductions in} service and additional intervention costs

Measuring resilience directly using reductions in service requires constructing a detailed representation of the transport system in appropriate models, simulating how the future might unfold when different hazard events occur and measuring the difference between the service provided when no hazard event occurred and when the hazard events occurred (as shown in Figure 4). For example, if the total simulated additional intervention costs due to a hazard event are $€ 1000000$ and the total simulated additional travel time costs due to a hazard event are $€ 1500000$, the resilience measure is $€ 2500000$. An example of a process to be used to develop simulation tools to measure resilience, and a simulation tool used to measure resilience, can be found in the publications by Adey et al. (2016) and Hackl et al. (2018b). The inputs and models to be used in running simulations are highly case dependent. It is recommended to use the modelling tools currently accepted by stakeholders as far as possible. This decreases analysis effort and increases acceptance of the results.

\section{Step 4: measure resilience using indicators}

Measuring resilience using indicators requires the selection of the relevant indicators. They should be selected to give an adequate indication of the difference between the service provided, and the intervention costs, with and without the occurrence of the hazard event:

- from the start of a hazard event to the end of a hazard event that is, during the absorption phase, including the expected reductions in service and additional intervention costs during the hazard event

- from the end of the hazard event to the time when service is again provided at the level it was before the event - that is, during the recovery phase, including the expected reductions in service and additional intervention costs during the restoration period.

This is to be done according to the actions shown in Figure 5 and explained in detail in the next four steps (i.e. 4.1 to 4.4 ).

\section{STEP 4.1: IDENTIFY RESILIENCE INDICATORS}

Resilience indicators should be identified by

- selecting each part of the transport system - that is, the infrastructure, the environment or the organisation - and then for that part
- developing categories of indicators at successive levels, until

- quantifiable indicators are identified that yield indications of the reductions in service and additional intervention costs if the hazard occurs and then

- determining the possible values of the indicators.

This hierarchical approach helps ensure that the indicators are as orthogonal as possible. An example is given in Table 6 using only the parts of the transportation system and the indicators and the small transport system example defined in step 1.

\section{STEP 4.2: CHECK THE RELEVANCY OF INDICATORS}

To ensure that all indicators are relevant, and that there are indications for all relevant aspects of the service provided by the infrastructure and intervention costs, the following question for each indicator should be asked for each measure of service and intervention costs: 'Does the change in the value of the indicator affect the expected value of the measure of service or intervention costs if a hazard event occurs and therefore the resilience of the infrastructure?'. For clarity, the connection between the indicator and resilience should be stated. For example, the higher the value of the seismic zone indicator, the higher the seismic zone in which a bridge is located. The higher the seismic zone in which a bridge is located, the higher the probability of the bridge being affected by an earthquake and therefore the higher the expected restoration intervention costs and additional travel time costs within a specific period of time. Assuming that everything else is constant, this means that the higher the value of the seismic zone, the lower the resilience of the transport infrastructure. The connections for the example indicator introduced in step 4.1 are shown in shortened form in Table 7.

\section{STEP 4.3: ESTIMATE THE VALUES OF THE INDICATORS}

Once the resilience indicators have been selected, the values (from the minimum to the maximum) of each have to be determined for the time period in question. The values should then be displayed to give

- an overview of the indicator values

- an indication of the resilience, and, if desired

an indication as to what can be done to improve the resilience. An example is given in Table 8 using only the parts of the transportation system and the indicators from the example defined in step 1 .

Table 6. Example resilience indicators

\begin{tabular}{|c|c|c|}
\hline Part & Indicator & Relation to phase \\
\hline Infrastructure & $\begin{array}{l}\text { Design resistance to hazard } \\
\text { Condition state }\end{array}$ & $\begin{array}{l}\text { Absorp phase - how an asset is prepared to react during a hazard event } \\
\text { Absorp phase - how the conditions of an asset influence its ability to react during a hazard event }\end{array}$ \\
\hline Environment & $\begin{array}{l}\text { Seismic zone } \\
\text { Regulatory framework }\end{array}$ & $\begin{array}{l}\text { Absorp phase - how an asset will be affected during a hazard event } \\
\text { Recovery phase - consequences after a hazard event }\end{array}$ \\
\hline Organisation & $\begin{array}{l}\text { Frequency of monitoring } \\
\text { Quality of emergency plan }\end{array}$ & $\begin{array}{l}\text { Recovery phase - consequences during a hazard event } \\
\text { Recovery phase - consequences during a hazard event }\end{array}$ \\
\hline
\end{tabular}




\begin{tabular}{|c|c|c|c|c|}
\hline \multirow[t]{2}{*}{ Indicator } & \multirow[t]{2}{*}{ Description } & \multicolumn{2}{|c|}{$\begin{array}{l}\text { An increase in the value of } \\
\text { the resilience indicator is } \\
\text { likely to result in ... the } \\
\text { expected additional ... } \\
\text { costs }\end{array}$} & \multirow[t]{2}{*}{$\begin{array}{l}\text { An increase in the value of the } \\
\text { resilience indicator, therefore, } \\
\text { means there is ... resilience }\end{array}$} \\
\hline & & Intervention & Travel time & \\
\hline Design resistance & $\begin{array}{l}\text { The higher the value of the design resistance } \\
\text { indicator, the higher the expected design } \\
\text { resistance of the bridge }\end{array}$ & A decrease in & A decrease in & An increase in \\
\hline Condition state & $\begin{array}{l}\text { The higher the value of the condition state } \\
\text { indicator, the better the condition state of the } \\
\text { bridge }\end{array}$ & A decrease in & A decrease in & An increase in \\
\hline Seismic zone & $\begin{array}{l}\text { The higher the value of the seismic zone indicator, } \\
\text { the more likely it is to have an earthquake of } \\
\text { magnitude } x\end{array}$ & An increase in & An increase in & A decrease in \\
\hline Regulatory framework & $\begin{array}{l}\text { The higher the value of the regulatory framework } \\
\text { indicator, the less likely it is that the responsible } \\
\text { organisation will have difficulties restoring service } \\
\text { following an earthquake of magnitude } x\end{array}$ & A decrease in & A decrease in & An increase in \\
\hline $\begin{array}{c}\text { Frequency of } \\
\text { monitoring }\end{array}$ & $\begin{array}{l}\text { The higher the value of the frequency of } \\
\text { monitoring indicator, the more likely it is that the } \\
\text { responsible organisation can react quickly to limit } \\
\text { transport disruptions following an earthquake }\end{array}$ & No change in & A decrease in & An increase in \\
\hline $\begin{array}{l}\text { Quality of } \\
\text { emergency plan }\end{array}$ & $\begin{array}{l}\text { The higher the value of the quality of the emergency } \\
\text { plan indictor, the faster the restoration is likely to } \\
\text { take place and, therefore, the lower the additional } \\
\text { travel time due to the earthquake }\end{array}$ & No change in & A decrease in & An increase in \\
\hline
\end{tabular}

\section{STEP 4.4: MEASURE RESILIENCE}

Measuring resilience using indicators, instead of measuring resilience directly, requires correlating the values of the indicators with resilience as well as possible. This can be done by assuming that there is a maximum reduction in service for each measure of service and a maximum amount of additional intervention costs due to each resilience indicator and they occur when that indicator alone has its worst value while all others have their best values. As the maximum reduction in service and the maximum amount of additional intervention costs can be estimated in two ways, they lead to two types of weights, as follows:

- differentiated resilience weights: where the maximum reductions in service and the maximum additional intervention costs are different for each resilience indicator

- equal resilience weights: where the maximum reductions in service and the maximum additional intervention costs are the same for each resilience indicator.

This is to be done according to the actions explained in detail in steps 4.5 and 4.6. For demonstrative purposes, Table 9 shows a value of each resilience indicator on the mentioned example transport system.

\section{STEP 4.5: MEASURE RESILIENCE USING DIFFERENTIATED RESILIENCE WEIGHTS}

Measuring resilience using differentiated resilience weights requires making a connection between the values of the indicators and the value of resilience. This can be done as follows.
- Imagine that all indicators have their best values, and estimate the reduction in service, for each measure of service, and additional intervention costs, if the hazard occurs.

- Imagine that each indicator has its worst value, and estimate the reduction in service for each measure of service and the additional intervention costs, if the hazard occurs.

- Assuming a relationship (e.g. linear) between the worst and best values for each indicator that is considered to be relevant for each measure of service and intervention costs and using the actual values of the indicators, measure the resilience.

Measuring resilience using differentiated resilience weights

- gives an indication of the reductions in service, for each measure of service, and the additional intervention costs

n gives an indication of the possible increase in service, and reduction in additional intervention costs, by improving the value of each resilience indicator

- gives an approximate consideration of the interactions between resilience indicators, by looking at higher levels of resilience indicators and resilience indicators categories, and often it requires less effort than measuring resilience directly, but is less accurate.

To support the theoretical explanation of this step, an example of how to measure the resilience with differentiated weights is here illustrated for the example transport infrastructure introduced in step 4.1. This is done using the maximum and minimum expected 
Table 8. Example resilience indicators

\begin{tabular}{|c|c|c|c|}
\hline Part & Indicator & Values from best to worst ${ }^{a}$ & Meaning \\
\hline \multirow{10}{*}{ Infrastructure } & Design resistance to hazard & 5 & Design code level 5 \\
\hline & & 4 & Design code level 4 \\
\hline & & 3 & Design code level 3 \\
\hline & & 2 & Design code level 2 \\
\hline & & 1 & Design code level 1 \\
\hline & Condition state of bridge & 5 & Like new \\
\hline & & 4 & Slightly deteriorated \\
\hline & & 3 & Average \\
\hline & & 2 & Poor \\
\hline & & 1 & Alarming \\
\hline \multirow[t]{8}{*}{ Environment } & Seismic zone & 5 & Very low seismic zone \\
\hline & & 4 & Low seismic zone \\
\hline & & 3 & Average seismic zone \\
\hline & & 2 & Moderate seismic zone \\
\hline & & 1 & Severe seismic zone \\
\hline & Regulatory framework & 3 & $\begin{array}{l}\text { Very few administrative hurdles to be crossed after the hazard } \\
\text { occurs }\end{array}$ \\
\hline & & 2 & Some administrative hurdles to be crossed after the hazard occurs \\
\hline & & 1 & $\begin{array}{l}\text { Significant administrative hurdles to be crossed after the hazard } \\
\text { occurs }\end{array}$ \\
\hline \multirow[t]{7}{*}{ Organisation } & Frequency of monitoring & 4 & Regular frequent monitoring \\
\hline & & 3 & Regular but infrequent monitoring \\
\hline & & 2 & Irregular monitoring \\
\hline & & 1 & No monitoring \\
\hline & Quality of emergency plan & 3 & Bridge-specific plan \\
\hline & & 2 & Generic plan \\
\hline & & 1 & No plan \\
\hline
\end{tabular}

a The best value is the one considered to be linked to the highest resilience, and the worst value is the one considered to be linked to the lowest resilience. There is, on purpose, no connection to the minimum or maximum value of the indicator. The absence of this connections facilitates the use of normally used indicators in different countries. For example, in some countries the best value of the condition state of an infrastructure is 1 and the worst value of the condition state is 5 , whereas in other countries it is reversed

Table 9. Values of resilience indicators

\begin{tabular}{|c|c|c|c|c|}
\hline Part & Indicator & Number of possible values & Value & Meaning of value ${ }^{a}$ \\
\hline \multirow{2}{*}{ Infrastructure } & Design resistance to hazard & 5 & 2 & Design code level 2 \\
\hline & Condition state & 5 & 4 & Slightly deteriorated \\
\hline \multirow[t]{2}{*}{ Environment } & Seismic zone & 5 & 3 & Average seismic zone \\
\hline & Regulatory framework & 3 & 1 & $\begin{array}{l}\text { Significant administrative hurdles to be crossed after the } \\
\text { hazard occurs }\end{array}$ \\
\hline \multirow[t]{2}{*}{ Organisation } & Frequency of monitoring & 4 & 1 & No monitoring \\
\hline & Quality of emergency plan & 3 & 3 & Bridge-specific plan \\
\hline
\end{tabular}

a The meanings of each of the possible values for the example are given in Table 8

reductions in service due to each resilience. Table 10 is to be read as it follows: if, for instance, all resilience indicators have their best values and the frequency of monitoring indicator has its worst value (1 out of 4 )

- the maximum additional travel time that might be incurred due to the disruption to the transport system while it is verified that the infrastructure can be used as intended could be $10000 \mathrm{~h}$, where if travel time is valued at $€ 15 / \mathrm{h}$, it would mean that the maximum additional travel time costs could be $€ 150000$ - the maximum additional intervention costs that might be incurred due to the restoration of the transport infrastructure from $A$ to $B$ could be $€ 0$ because the bridge would not fail and no intervention costs due to restoration would occur. 
Table 10. Maximum and minimum expected reductions in service due to each resilience indicator for each measure of service using differentiated weights

\begin{tabular}{|c|c|c|c|c|c|c|c|}
\hline \multirow{2}{*}{ Part } & \multirow{2}{*}{ Indicator } & \multirow{2}{*}{$\begin{array}{c}\text { Best or } \\
\text { worst value }\end{array}$} & \multirow{2}{*}{ Value } & \multirow{2}{*}{$\begin{array}{l}\text { Maximum expected additional } \\
\text { intervention costs: } €\end{array}$} & \multicolumn{2}{|c|}{$\begin{array}{l}\text { Maximum expected } \\
\text { reductions in service }\end{array}$} & \multirow{2}{*}{$\begin{array}{l}\text { Maximum expected } \\
\text { total costs: } €\end{array}$} \\
\hline & & & & & $\begin{array}{l}\text { Travel } \\
\text { time: } \mathrm{h}\end{array}$ & $\begin{array}{l}\text { Travel time } \\
\text { costs: } €\end{array}$ & \\
\hline \multirow[t]{4}{*}{ Infrastructure } & \multirow{4}{*}{$\begin{array}{l}\text { Design resistance } \\
\text { to hazard } \\
\text { Condition state } \\
\text { of bridge }\end{array}$} & Best & 5 & $0^{a}$ & 0 & 0 & 0 \\
\hline & & Worst & 1 & 500000 & 100000 & 1500000 & 2000000 \\
\hline & & Best & 5 & 0 & 0 & 0 & 0 \\
\hline & & Worst & 1 & 100000 & 70000 & 1050000 & 1150000 \\
\hline \multirow[t]{4}{*}{ Environment } & \multirow[t]{2}{*}{ Seismic zone } & Best & 5 & 0 & 0 & 0 & 0 \\
\hline & & Worst & 1 & 1000000 & 100000 & 1500000 & 2500000 \\
\hline & \multirow{2}{*}{$\begin{array}{l}\text { Regulatory } \\
\text { framework }\end{array}$} & Best & 3 & 0 & 0 & 0 & 0 \\
\hline & & Worst & 1 & $0^{b}$ & 60000 & 900000 & 900000 \\
\hline \multirow[t]{4}{*}{ Organisation } & \multirow{2}{*}{$\begin{array}{c}\text { Frequency of } \\
\text { monitoring }\end{array}$} & Best & 4 & 0 & 0 & 0 & 0 \\
\hline & & Worst & 1 & $0^{\mathrm{b}}$ & 10000 & 150000 & 150000 \\
\hline & \multirow{2}{*}{$\begin{array}{l}\text { Quality of } \\
\text { emergency plan }\end{array}$} & Best & 3 & 0 & 0 & 0 & 0 \\
\hline & & Worst & 1 & $0^{\mathrm{b}}$ & 50000 & 750000 & 750000 \\
\hline
\end{tabular}

${ }^{a}$ Although in this example the maximum expected additional intervention costs and reductions in service for the best value of the indicator are assumed to be zero, this does not have to be the case. It might be reasonable to believe that if an indicator has its best value that there would still be additional intervention costs if a hazard event occurred. The values of zero are used here for simplicity of clarification

${ }^{b}$ When the costs associated with the best and worst values of a resilience indicator are the same, it means that the indicator is not relevant for this measure of service or intervention cost

With the maximum and minimum expected reductions in service estimated, the resilience is measured using the resilience value of each indicator (Table 11), while in Table 12, the measure is done for parts of the transport system. In Figure 6, the resilience measures with differentiated weights are shown for each type of cost and for the total cost.

\section{STEP 4.6: MEASURE RESILIENCE USING EQUAL RESILIENCE WEIGHTS}

Measuring the resilience using equal resilience weights is done the same way than with the differentiated weight, only considering that each indicator has the same importance, as described in step 4.4. For example, for the same transport infrastructure used in step 4.5, if all resilience indicators have their worst values (Table 13)

- the maximum additional intervention costs that might be incurred due to the restoration of the transport infrastructure from A to B might be estimated as $€ 1000000$

- the maximum additional travel time that might be incurred could be estimated as $100000 \mathrm{~h}$, where if travel time is valued at $€ 15 / \mathrm{h}$, it would mean that the maximum additional travel time costs might be estimated as $€ 1500000$.

Table 11. Resilience measures using indicators and differentiated resilience weights

\begin{tabular}{|cccccccc} 
Part & Indicator & $\begin{array}{c}\text { Number of } \\
\text { possible values }\end{array}$ & Value & $\begin{array}{c}\text { Maximum expected additional } \\
\text { intervention costs: } €\end{array}$ & $\begin{array}{c}\text { Maximum expected } \\
\text { reductions in service }\end{array}$ & $\begin{array}{c}\text { Maximum } \\
\text { Travel } \\
\text { time: } \mathrm{h} \text { Travel time } \\
\text { costs: } €\end{array}$ \\
costs: $€$
\end{tabular}

${ }^{a}$ Using differentiated weights, it is shown that the largest contributor to the lack of resilience is the design resistance to hazard resilience indicator (i.e. $€ 1500000$ )

$\mathrm{b}$ The quality of the emergency plan resilience indicator is the smallest contributor to the lack of resilience. This is because it is already considered to be as good as possible 
Table 12. Resilience measures using transport system parts and differentiated resilience weights

\begin{tabular}{|c|c|c|c|c|c|c|c|}
\hline \multirow{2}{*}{ Part } & \multirow{2}{*}{ Indicator } & \multirow{2}{*}{$\begin{array}{c}\text { Number of } \\
\text { possible values }\end{array}$} & \multirow{2}{*}{ Value } & \multirow{2}{*}{$\begin{array}{l}\text { Maximum expected additional } \\
\text { intervention costs: } €\end{array}$} & \multicolumn{2}{|c|}{$\begin{array}{l}\text { Maximum expected } \\
\text { reductions in service }\end{array}$} & \multirow{2}{*}{$\begin{array}{l}\text { Maximum expected } \\
\text { total costs: } €\end{array}$} \\
\hline & & & & & $\begin{array}{l}\text { Travel } \\
\text { time: } \mathrm{h}\end{array}$ & $\begin{array}{l}\text { Travel time } \\
\text { costs: } €\end{array}$ & \\
\hline \multirow[t]{2}{*}{ Infrastructure } & Design resistance & 5 & 2 & \multirow[b]{2}{*}{400000} & \multirow[b]{2}{*}{92500} & \multirow[b]{2}{*}{1387500} & \multirow[b]{2}{*}{1787500} \\
\hline & $\begin{array}{l}\text { Condition state } \\
\text { of bridge }\end{array}$ & 5 & 4 & & & & \\
\hline \multirow{2}{*}{ Environment } & Seismic zone & 5 & 3 & \multirow[b]{2}{*}{500000} & \multirow[b]{2}{*}{110000} & \multirow[b]{2}{*}{1650000} & \multirow[b]{2}{*}{$2150000^{a}$} \\
\hline & $\begin{array}{l}\text { Regulatory } \\
\text { framework }\end{array}$ & 3 & 1 & & & & \\
\hline \multirow[t]{2}{*}{ Organisation } & Frequency of & 4 & 1 & \multirow[b]{2}{*}{0} & \multirow[b]{2}{*}{10000} & \multirow[b]{2}{*}{150000} & \multirow[b]{2}{*}{$150000^{b}$} \\
\hline & $\begin{array}{l}\text { monitoring } \\
\text { Quality of } \\
\text { emergency plan }\end{array}$ & 3 & 3 & & & & \\
\hline
\end{tabular}

${ }^{a}$ At the part level, one sees a view slightly different from that at the lower levels, because there are multiple resilience indicators for part of the transport system. It is shown that the largest contributor to the lack of resilience is the environment (i.e. $€ 2150000$ )

${ }^{\mathrm{b}}$ The smallest contributor to the lack of resilience is the organisation (€150 000). This is because the frequency of monitoring is considered to have a relatively small effect on resilience, and the quality of the emergency plan resilience indicator has the highest value possible

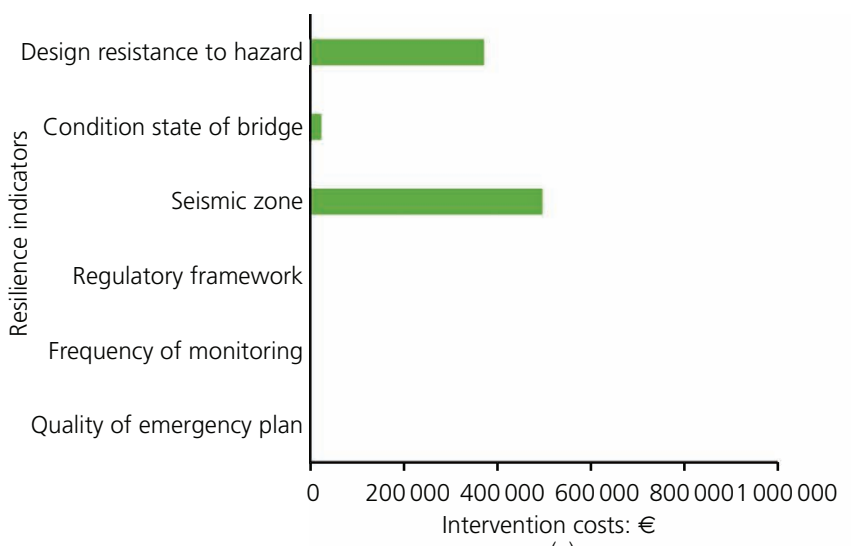

(a)

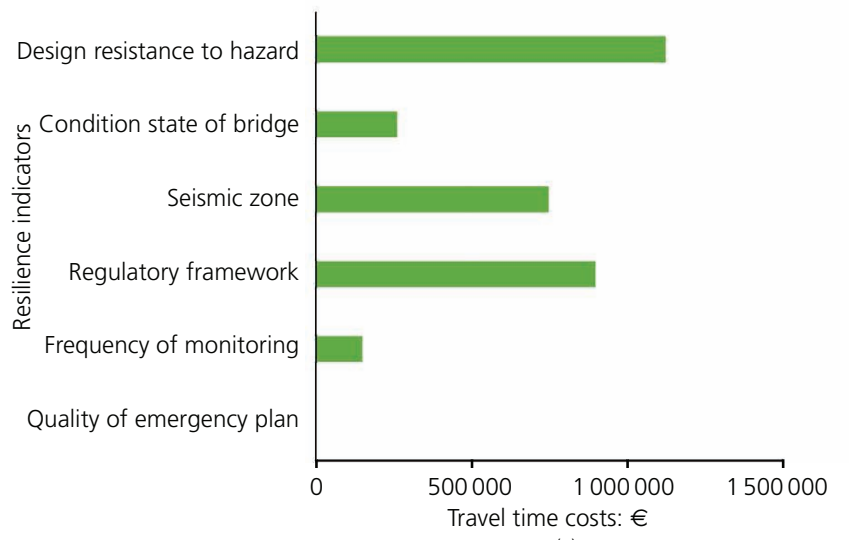

(c)

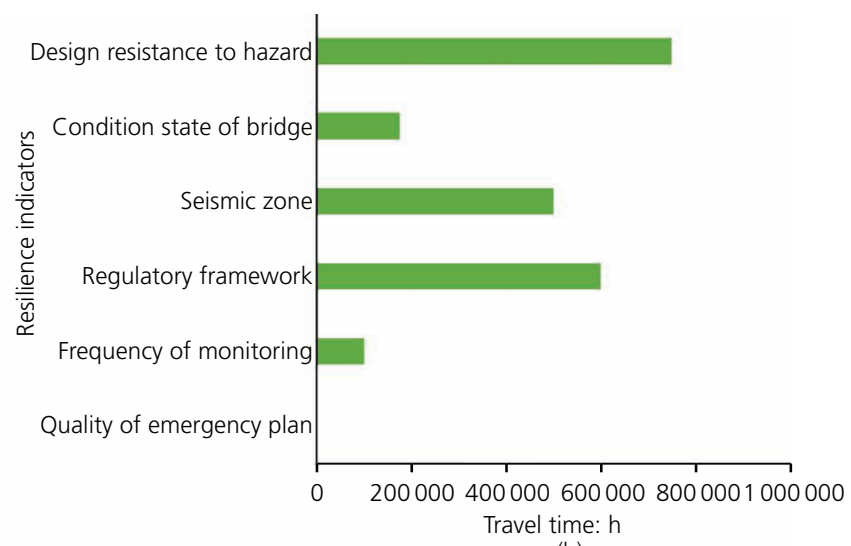

(b)

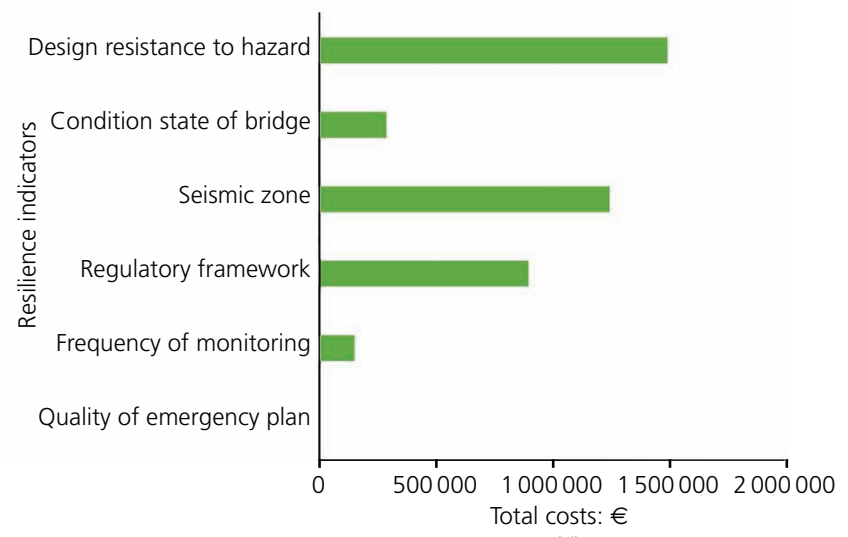

(d)

Figure 6. Resilience measures using indicators and using differentiated weights: (a) intervention costs; (b) travel time; (c) travel time costs; (d) total costs 
Table 13. Maximum and minimum expected reductions in service due to the values of resilience indicators for each measure of service using equal weights

\begin{tabular}{|c|c|c|c|c|c|c|c|}
\hline \multirow{2}{*}{ Part } & \multirow{2}{*}{ Indicator } & \multirow{2}{*}{$\begin{array}{l}\text { Best or } \\
\text { worst value }\end{array}$} & \multirow{2}{*}{ Value } & \multirow{2}{*}{$\begin{array}{l}\text { Maximum expected additional } \\
\text { intervention costs: } €\end{array}$} & \multicolumn{2}{|c|}{$\begin{array}{l}\text { Maximum expected } \\
\text { reductions in service }\end{array}$} & \multirow{2}{*}{$\begin{array}{l}\text { Maximum expected } \\
\text { total costs: } €\end{array}$} \\
\hline & & & & & $\begin{array}{l}\text { Travel } \\
\text { time: } \mathrm{h}\end{array}$ & $\begin{array}{l}\text { Travel time } \\
\text { costs: } €\end{array}$ & \\
\hline \multirow[t]{4}{*}{ Infrastructure } & \multirow{4}{*}{$\begin{array}{l}\text { Design resistance } \\
\text { to hazard } \\
\text { Condition state } \\
\text { of bridge }\end{array}$} & Best & 5 & 0 & 0 & 0 & 0 \\
\hline & & Worst & 1 & 1000000 & 100000 & 1500000 & 2500000 \\
\hline & & Best & 5 & 0 & 0 & 0 & 0 \\
\hline & & Worst & 1 & 1000000 & 100000 & 1500000 & 2500000 \\
\hline \multirow[t]{4}{*}{ Environment } & \multirow[t]{2}{*}{ Seismic zone } & Best & 5 & 0 & 0 & 0 & 0 \\
\hline & & Worst & 1 & 1000000 & 100000 & 1500000 & 2500000 \\
\hline & \multirow{2}{*}{$\begin{array}{l}\text { Regulatory } \\
\text { framework }\end{array}$} & Best & 3 & 0 & 0 & 0 & 0 \\
\hline & & Worst & 1 & 0 & 100000 & 1500000 & 1500000 \\
\hline \multirow[t]{4}{*}{ Organisation } & \multirow{2}{*}{$\begin{array}{c}\text { Frequency of } \\
\text { monitoring }\end{array}$} & Best & 4 & $0^{\mathrm{a}}$ & 0 & 0 & 0 \\
\hline & & Worst & 1 & 0 & 100000 & 1500000 & $1500000^{b}$ \\
\hline & \multirow{2}{*}{$\begin{array}{l}\text { Quality of } \\
\text { emergency plan }\end{array}$} & Best & 3 & $0^{\mathrm{a}}$ & 0 & 0 & 0 \\
\hline & & Worst & 1 & 0 & 100000 & 1500000 & 1500000 \\
\hline
\end{tabular}

${ }^{a}$ When the worst and best values are the same, it reflects the fact that the indicator is not relevant for this measure of service or the intervention costs

${ }^{b}$ The worst and best values of the total costs encompass the fact that not all relevant indicators affect all relevant service types. Because frequency of monitoring and quality of emergency plan do not affect intervention costs, the effect of these indicators on the resilience of the transport system is lower than the other indicators (€1 500000 is less than $€ 2500000$ )

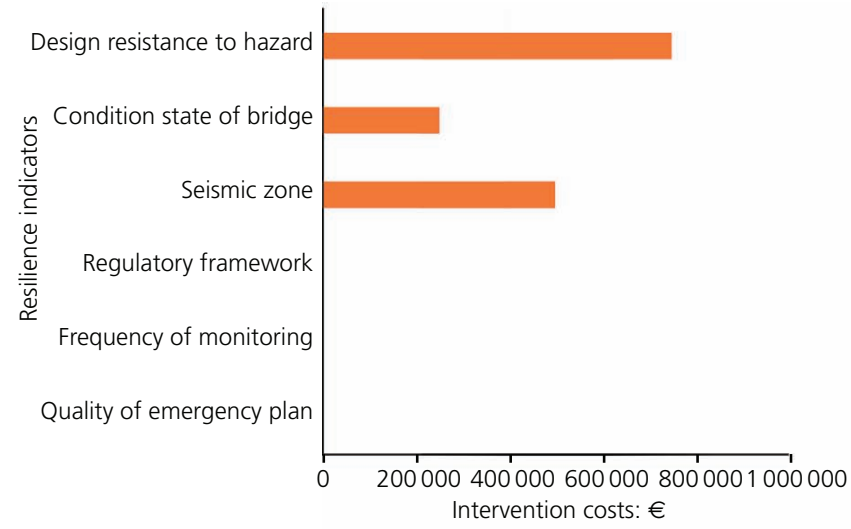

(a)

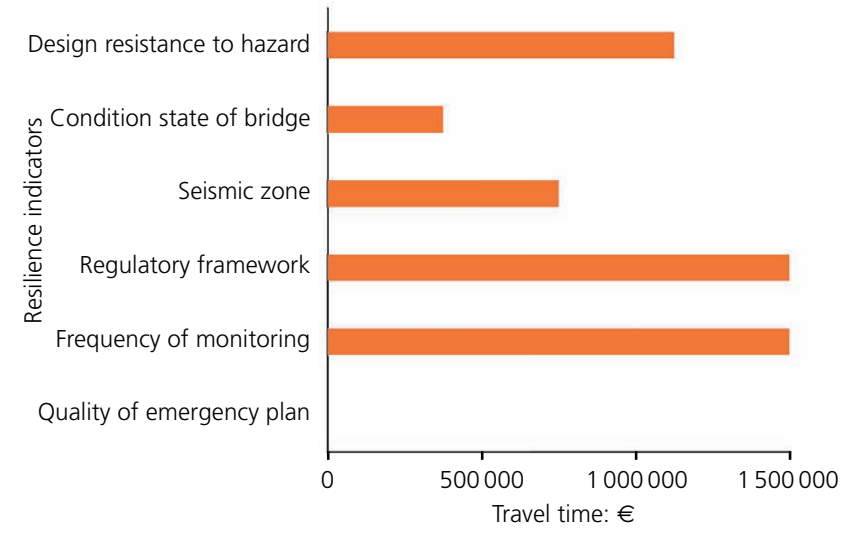

(c)

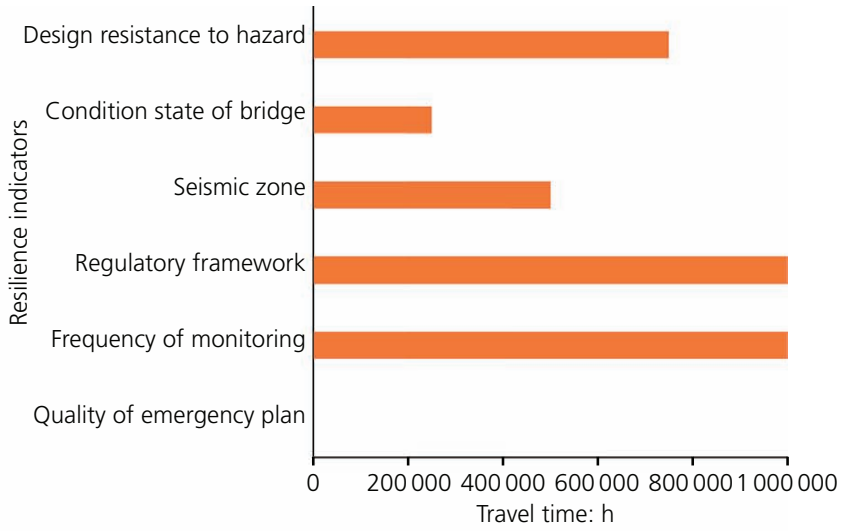

(b)

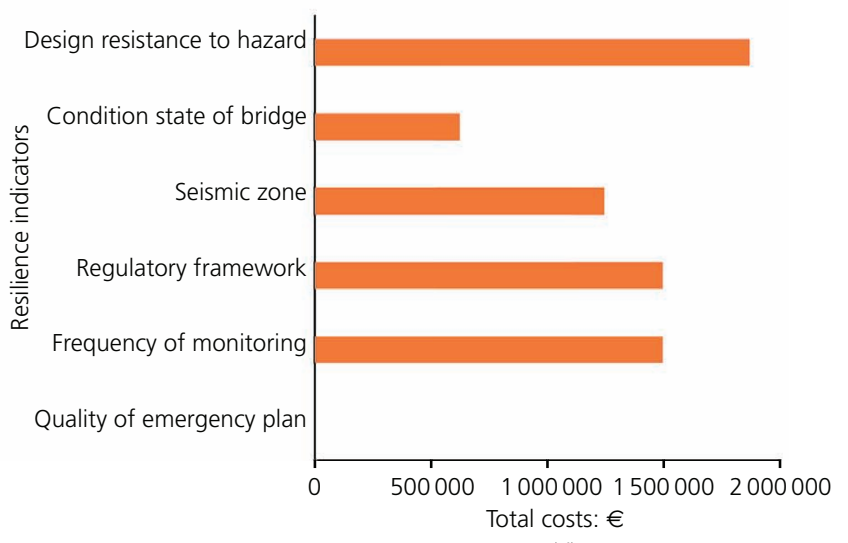

(d)

Figure 7. Resilience measures using resilience indicators and equal resilience weights: (a) intervention costs; (b) travel time; (c) travel time costs; (d) total costs 
From these values, using the same logic as from Tables 11 and 12 with the differentiated weights, with the equal weights, the resilience can be also measured considering the resilience value of each indicator, as well as for parts of the transport system. In Figure 7, the resilience measures with equal weights are shown for each type of cost and for the total cost.

\section{Step 5: estimate the percentage of fulfilment of the resilience indicators}

Once a measure of resilience exists, it is often useful to have an overview of the percentage of fulfilment of resilience indicators and resilience indicator categories, to have an idea of where to concentrate efforts to improve resilience. This can be done using (a) differentiated resilience weights - that is, the worst value of each indicator represents the maximum reduction in service, for each measure of service, and the maximum additional intervention costs for each relevant indicator; $(b)$ equal resilience weights that is, the worst value of each indicator represents the maximum reduction in service, for each measure of service, and the maximum additional intervention costs for all relevant indicators; and $(c)$ no weights. The percentages of fulfilment of a resilience indicator using the resilience weights (both the equal and the differentiated weights) are calculated as 1 minus the expected reductions in service and the additional intervention costs due to the value of the indicator divided by the maximum reductions in service and additional intervention costs if the indicator has its worst value, while the percentages of fulfilment of a resilience indicator using no weights are calculated as the average of the percentage of fulfilment of the indicators or indicator categories. For example, when using the differentiated resilience weights, the percentage of fulfilment of the resilience indicators, is estimated as shown in Table 14 and Figure 8. The logic with which this is built is described as follows.

- The expected reductions in service and additional intervention costs attributed to the indicators representing the organisation part of the transport system (from Table 10) are $€ 150000$, which is composed of $€ 150000$ of travel time costs and $€ 0$

Table 14. Percentages of fulfilment with equal resilience weights

\begin{tabular}{|c|c|c|c|c|c|}
\hline \multirow[t]{2}{*}{ Part } & \multirow[t]{2}{*}{ Indicator } & \multirow[t]{2}{*}{ Number of possible values } & \multirow[t]{2}{*}{ Value } & \multicolumn{2}{|c|}{$\begin{array}{l}\text { Percentage of fulfilment of indicators and indicator } \\
\text { categories using equal weights }\end{array}$} \\
\hline & & & & Of resilience indicators & Of parts \\
\hline \multirow[t]{2}{*}{ Infrastructure } & Design resistance to hazard & 5 & 2 & 0.25 & 0.433 \\
\hline & Condition state of bridge & 5 & 4 & 0.75 & \\
\hline \multirow[t]{2}{*}{ Environment } & Seismic zone & 5 & 3 & 0.5 & $0.368^{c}$ \\
\hline & Regulatory framework & 3 & 1 & 0 & \\
\hline \multirow[t]{2}{*}{ Organisation } & Frequency of monitoring & 4 & 1 & $0^{a}$ & 0.833 \\
\hline & Quality of emergency plan & 3 & 3 & $1^{\mathrm{b}}$ & \\
\hline
\end{tabular}

${ }^{a}$ The resilience indicator with the worst value is the frequency of monitoring resilience indicator, which is $0 \%$ fulfilled - that is, a value 1 of 4

${ }^{b}$ The resilience indicator with the best value is the quality of emergency plan resilience indicator, which is $100 \%$ fulfilled - that is, a value of 3 of 3

c Using differentiated resilience weights, the percentages of fulfilment of the parts of the transport system categories show that the environment resilience indicators are only $36.8 \%$ fulfilled. This is less than $25 \%$ that one might expect because the seismic zone resilience indicator has a greater weight - that is, it has more effect on resilience, than the regulatory framework resilience indicator

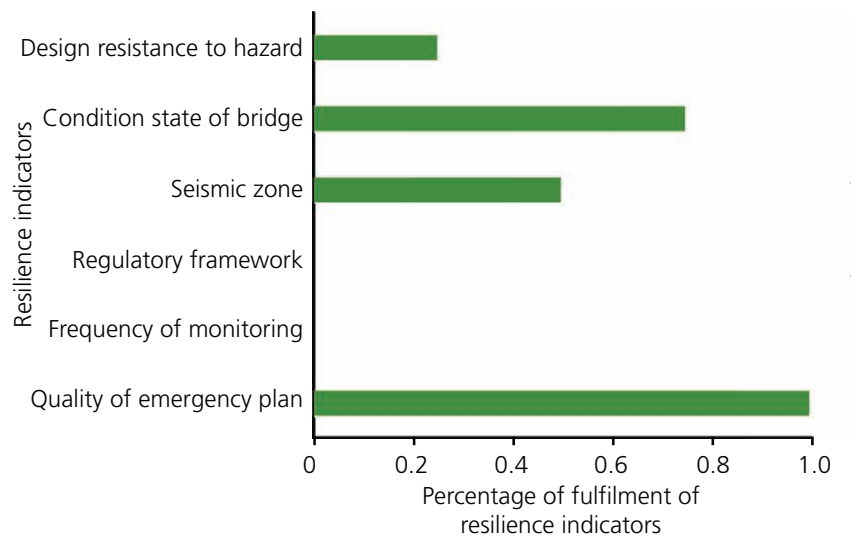

(a)

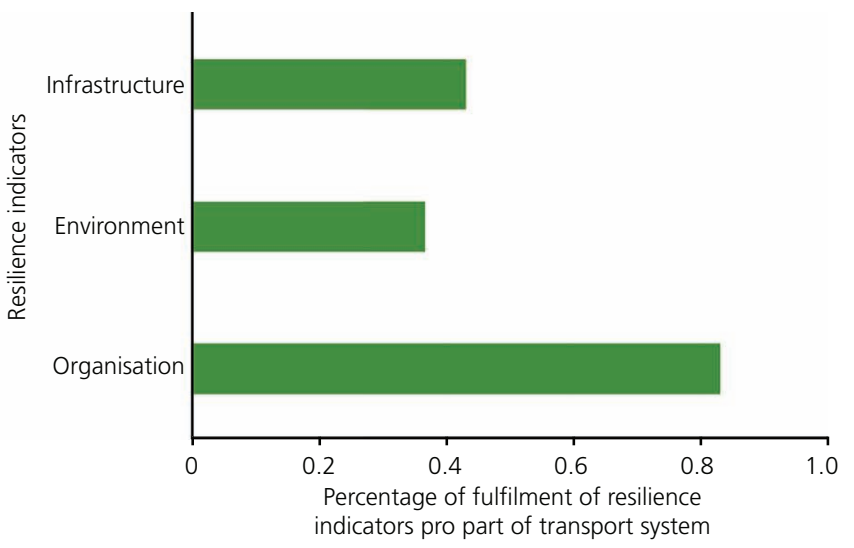

(b)

Figure 8. Percentages of fulfilment using differentiated resilience weights: (a) indicators; (b) indicators grouped by part of the transport system 
intervention costs and due to the frequency of monitoring indicator and $€ 0$ of travel time costs and $€ 0$ intervention costs due to the quality of the emergency plan indicator.

n The maximum expected reductions in service and additional intervention costs due to the value of the indicators are $€ 900000$, which is composed of $€ 150000$ travel time costs and $€ 0$ intervention costs due to the frequency of monitoring indicator and $€ 750000$ of travel time costs and $€ 150000$ intervention costs due to the quality of emergency plan indicator.

- The percentage of fulfilment is, therefore, $1-€ 150000 /$ $€ 900000=83.33 \%$.

The calculation is 1 minus the sum of the reductions in service and additional intervention costs due to each indicator, or indicator category, taking into consideration their current value divided by the sum of the total reductions in service and additional intervention costs due to each indicator, or indicator category. For the infrastructure part of the transport system - for example,

$$
\begin{aligned}
& 1-(500000+750000+900000) \\
& \text { 1. } /(1000000+1500000+900000)=0.368
\end{aligned}
$$

Similarly, when using the equal resilience weights and no resilient weights, the percentage of fulfilment of the resilience indicators, is estimated as reported in Table 15 and shown in Figure 9. Here the maximum reductions in service and additional intervention costs due to the value of the indicators (from Table 13) is $€ 3000000$, which is composed of $€ 1500000$ travel time costs and $€ 0$ intervention costs due to the frequency of monitoring and $€ 1500000$ of travel time costs and $€ 0$ intervention costs due to the quality of the emergency plan. The percentage of fulfilment is, therefore, $1-€ 1500000 / € 3000000=50 \%$.

Finally, when using no resilient weights, the percentage of fulfilment of the resilience indicators is estimated as reported in Table 16 and shown in Figure 10. In this case, the indicators

\begin{tabular}{|c|c|c|c|c|c|}
\hline \multirow[t]{2}{*}{ Part } & \multirow[t]{2}{*}{ Indicator } & \multirow[t]{2}{*}{ Number of possible values } & \multirow[t]{2}{*}{ Value } & \multicolumn{2}{|c|}{$\begin{array}{l}\text { Percentage of fulfilment of indicators and indicator } \\
\text { categories using equal weights }\end{array}$} \\
\hline & & & & Of resilience indicators & Of parts \\
\hline \multirow[t]{2}{*}{ Infrastructure } & Design resistance to hazard & 5 & 2 & 0.25 & \multirow[t]{2}{*}{0.5} \\
\hline & Condition state of bridge & 5 & 4 & 0.75 & \\
\hline \multirow[t]{2}{*}{ Environment } & Seismic zone & 5 & 3 & 0.5 & \multirow[t]{2}{*}{$0.3125^{c}$} \\
\hline & Regulatory framework & 3 & 1 & 0 & \\
\hline \multirow[t]{2}{*}{ Organisation } & Frequency of monitoring & 4 & 1 & $0^{a}$ & \multirow[t]{2}{*}{0.5} \\
\hline & Quality of emergency plan & 3 & 3 & $1^{\mathrm{b}}$ & \\
\hline
\end{tabular}

Table 15. Percentages of fulfilment with equal resilience weights

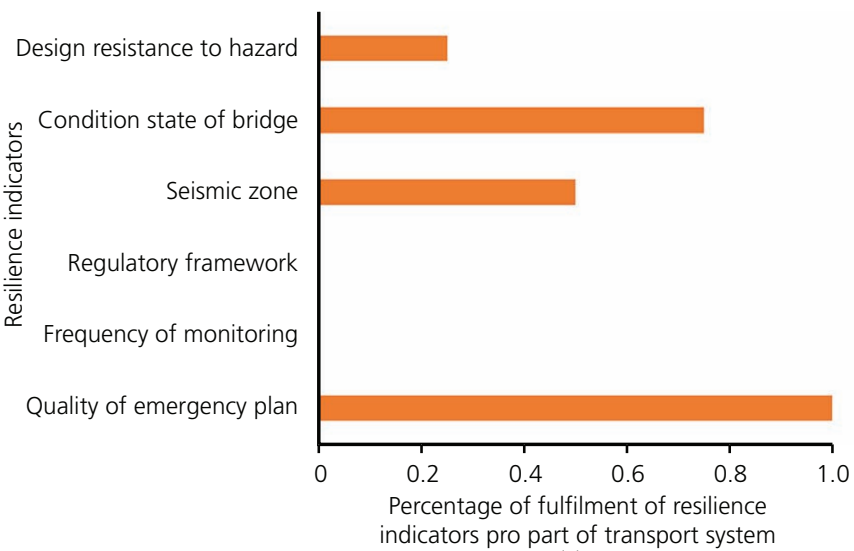

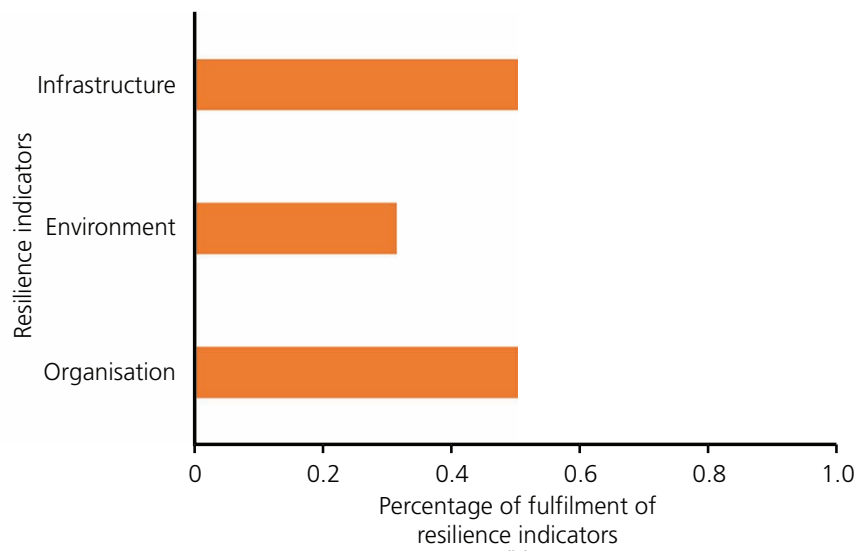

(b)

Figure 9. Percentages of fulfilment using equal resilience weights: (a) indicators; (b) indicators grouped for part of the transport system 
Table 16. Percentages of fulfilment with no resilience weights

\begin{tabular}{|c|c|c|c|c|c|}
\hline \multirow[t]{2}{*}{ Part } & \multirow[t]{2}{*}{ Indicator } & \multirow[t]{2}{*}{ Number of possible values } & \multirow[t]{2}{*}{ Value } & \multicolumn{2}{|c|}{$\begin{array}{l}\text { Percentage of fulfilment of indicators and indicator } \\
\text { categories using equal weights }\end{array}$} \\
\hline & & & & Of resilience indicators & Of parts \\
\hline \multirow[t]{2}{*}{ Infrastructure } & Design resistance to hazard & 5 & 2 & 0.25 & 0.5 \\
\hline & Condition state of bridge & 5 & 4 & 0.75 & \\
\hline \multirow[t]{2}{*}{ Environment } & Seismic zone & 5 & 3 & 0.5 & $0.25^{c}$ \\
\hline & Regulatory framework & 3 & 1 & 0 & \\
\hline \multirow[t]{2}{*}{ Organisation } & Frequency of monitoring & 4 & 1 & $0^{a}$ & 0.5 \\
\hline & Quality of emergency plan & 3 & 3 & $1^{\mathrm{b}}$ & \\
\hline
\end{tabular}

${ }^{a}$ The resilience indicator with the worst value is the frequency of monitoring resilience indicator, which is $0 \%$ fulfilled - that is, a value 1 of 4

${ }^{\mathrm{b}}$ The resilience indicator with the best value is the quality of emergency plan resilience indicator, which is $100 \%$ fulfilled - that is, a value of 3 of 3

' Using no resilience weights, the percentages of fulfilment of the parts of the transport system categories show that the environment resilience indicators are $25 \%$ fulfilled

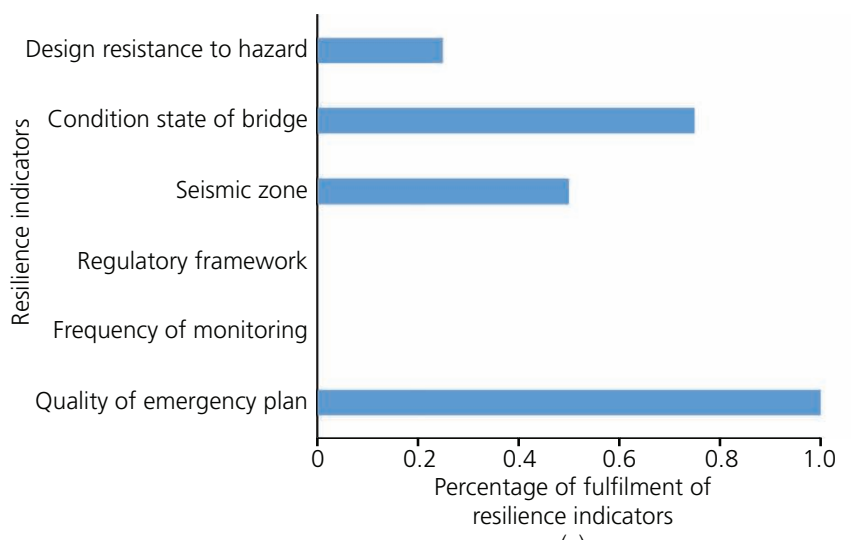

(a)

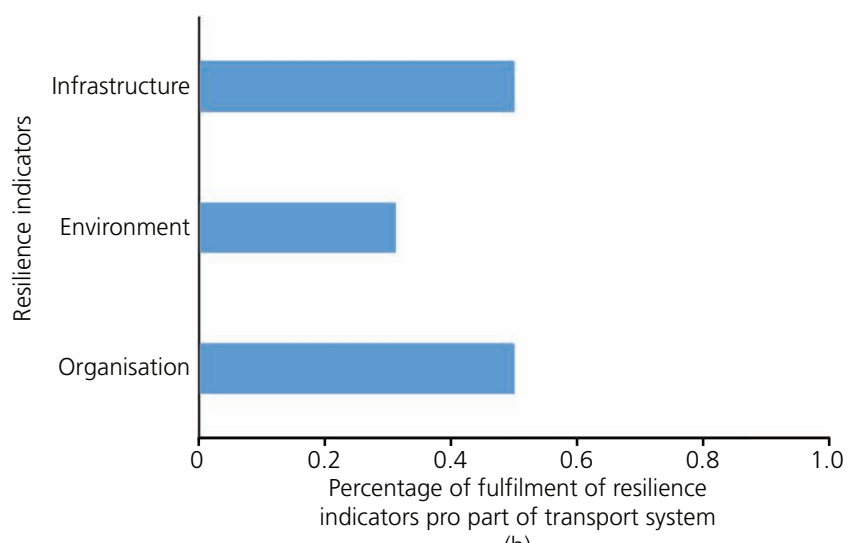

(b)

Figure 10. Percentages of fulfilment using no resilience weights: (a) indicators; (b) indicators grouped by part of the transport system

representing the organisation part of the transport system have the two resilience indicators - that is, the frequency of monitoring resilience indicator and the quality of the emergency plan resilience indicator, which are 0 and $100 \%$ fulfilled. The indicators representing the organisation part of the transport system can, therefore, be considered to be $(0+1) / 2=50 \%$ fulfilled.

\section{Set the service and resilience targets}

For the definition of the set service and resilience targets of an infrastructure, the process developed by Kielhauser et al. (2019) comprises the following four basic tasks: gather all relevant stakeholders, determine legal requirements, determine stakeholder requirements and set targets, where the specific method to be used depends on

- how resilience is measured - that is, using simulations or indicators

- whether or not cost-benefit analysis is to be used - that is, whether or not the targets are to be set by expert opinion or by explicitly taking into consideration both the cost of improving resilience and their effect on reducing the negative consequences in terms of restoration costs and losses of services if resilience is not improved.

If service and resilience are measured using simulations, targets are set for each of the target types (e.g. maximum allowed restoration time or shape of increase in intervention costs or decrease in service). If service and resilience are measured using indicators, targets are set on the values of the indicators. Targets are set either with or without cost-benefit analysis. The choice of whether to use cost-benefit analysis depends on how service and resilience are to be measured, the information available and the time and expertise available. If the information, time and expertise are available, cost-benefit analysis should be used. If they are not available, targets are to be set using expert opinion. The outline of the process is presented in Figure 11 and explained in the following text.

\section{Step 1: gather all relevant stakeholders}

In this task, all relevant stakeholders are gathered, whose opinion on setting the service and resilience targets, or the resilience indicator targets, should be considered. This is greatly dependent on the transport system itself and the potential scope of the 


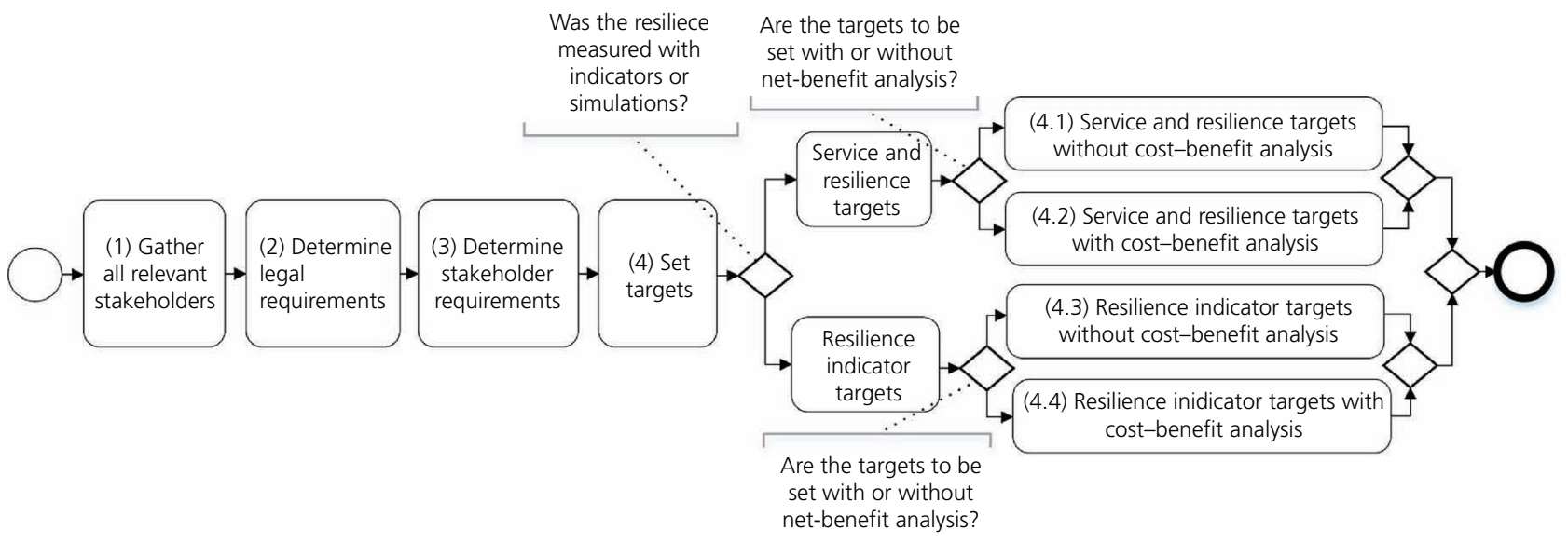

Figure 11. Process to set the service and resilience targets

service and resilience targets or the resilience indicator targets. For example, if service and resilience targets are to be set based only on intervention costs, the relevant stakeholders will encompass only those managing the infrastructure and those providing financial contributions.

\section{Step 2: determine legal requirements}

In this step, the legal requirements for service and resilience targets, or resilience indicator targets, are determined. Examples of legal requirements from laws or contractual agreements that prescribe service or resilience targets are annual average level of service, limits on the maximum number of expected accidents/period and speed limits (decided by the regulator to control the amount of nitrogen oxide $\left(\mathrm{NO}_{x}\right)$ gases that are emitted). Examples of legal requirements for resilience indicator targets are levels of redundancy in transport networks, the condition of a bridge has to be 4 or better, the design resistance has to be at least that specified in a specific national code and the frequency of monitoring has to be every 2 years or less. As these originate from various sources - for example, general laws and concessionaire contracts - and obtaining a complete list often requires a considerable effort, legal specialists should be tasked with identifying these requirements. Some sample legal requirements for the example transport system introduced in the section headed 'Measure service' are shown in Table 17.

\section{Step 3: determine stakeholder requirements}

In this step, the requirements of the stakeholders, besides legal requirements, are determined. Examples influencing the service and resilience targets are restrictions on the types of restoration interventions that can be executed due to the design of the transport network, restrictions on the type of equipment that can be used in restoration activities because of accessibility, specifications on the type of monitoring activities required following the occurrence of a natural hazard, specifications on the number of staff required per restoration activity, specifications as to the number of emergency response teams available in extreme situations or expectations that connectivity is to be restored as fast as possible following a hazard. Examples for resilience indicators targets are the condition state of a bridge must be above 3 and the design resistance of all bridges must be better than that prescribed

Table 17. Legal requirements for indicators

\begin{tabular}{|c|c|c|c|c|}
\hline Part & Indicator & Values from best to worst & Meaning & Target \\
\hline \multirow[t]{10}{*}{ Infrastructure } & \multirow[t]{5}{*}{ Design resistance to hazard } & 5 & Design code level 5 & \multirow{5}{*}{$\begin{array}{l}\text { Legal code requirement: value } 2 \\
\text { Concessionaire's contract: value } 3\end{array}$} \\
\hline & & 4 & Design code level 4 & \\
\hline & & 3 & Design code level 3 & \\
\hline & & 2 & Design code level 2 & \\
\hline & & 1 & Design code level 1 & \\
\hline & \multirow[t]{5}{*}{ Condition state of bridge } & 5 & Like new & \multirow[t]{5}{*}{ Legal requirement: value 2} \\
\hline & & 4 & Slightly deteriorated & \\
\hline & & 3 & Average & \\
\hline & & 2 & Poor & \\
\hline & & 1 & Alarming & \\
\hline \multirow[t]{3}{*}{ Organisation } & \multirow[t]{3}{*}{ Quality of emergency plan } & 3 & Bridge-specific plan & \multirow[t]{3}{*}{ Legal requirement: value 2} \\
\hline & & 2 & Generic plan & \\
\hline & & 1 & No plan & \\
\hline
\end{tabular}


by the most recent code. There are resilience indicators for which it is meaningless to set a target. For example, the seismic zone in which a bridge is located is an indicator of the level of service that it will provide following a hazard event, and of its resilience, but as it cannot be changed, it makes little sense to set a target seismic zone for the bridge.

\section{Step 4: set targets}

In this step, the targets are set. The next four subsections show the different methods, depending on whether service and resilience are measured directly or with indicators, and whether or not cost-benefit analysis should be used.

\section{STEP 4.1: SERVICE AND RESILIENCE TARGETS WITHOUT COST-BENEFIT ANALYSIS}

In this method, the service and resilience targets are set taking into consideration the requirements defined in the previous two steps and by using direct measures of service and resilience without cost-benefit analysis. The previously defined requirements set limits on possible targets. Setting targets requires the opinion of domain experts and the involved stakeholders. As this is often a highly iterative task, sufficient time should be planned to reach a widely supported agreement. The targets should be set, or consciously not set, for

- each type of target

- each type of intervention costs and measures of service

- each combination of intervention costs and measures of service

- each combination of type and intensity of hazards considered.

In setting the targets, the interdependencies between the intervention costs and measures of service should be considered - for example, it may not be wise to target very low intervention costs following a hazard event and very low amounts of additional travel time. Once the targets are set, it should be determined how they are measured. An example of targets and methods of measurements are shown in Table 18 for the indicators listed in the previous section, for one earthquake event within 3 years - that is, the targets should be met for one single earthquake and another happening 4 years later but need not to be met if the second earthquake happens 2 years after the first. This task should conclude with a set of targets that are broadly accepted by the stakeholders.

\section{STEP 4.2: SERVICE AND RESILIENCE TARGETS WITH COST-BENEFIT ANALYSIS}

Setting service and resilience targets with cost-benefit analysis can be summarised as collecting all necessary expert opinions to formulate sets of service and resilience targets that take into consideration all aspects of the transport system that are deemed important. This includes the interdependencies between intervention costs and measures of service while selecting the scenario and set of targets that has broad stakeholder support and yields the maximum net benefit. The targets are formulated so that it is clear how they are to be measured. In this method, the service and resilience targets are set, taking into consideration the requirements defined in the previous two steps, and the benefits and costs of achieving the targets. It is similar to that described in step 4.1, with the exception that the costs and benefits of achieving the targets are explicitly estimated. The sub-tasks required to do this are as follows.

(a) Select the types of targets to be set for restoration intervention costs and each measure of service - for example, for a 100-year flood event, targets might be set on the maximum increase in restoration intervention costs and the maximum acceptable restoration time - that is, allowed time

Table 18. Example resilience indicator targets

\begin{tabular}{|c|c|c|c|c|c|}
\hline Part & Indicator & $\begin{array}{l}\text { Values from } \\
\text { best to worst }\end{array}$ & Meaning & Target & Measurement \\
\hline \multirow[t]{10}{*}{ Infrastructure } & \multirow[t]{5}{*}{ Design resistance to hazard } & 5 & Design code level 5 & \multirow{5}{*}{$\begin{array}{l}\text { Legal requirement: } 2 \\
\text { Agreed-on target: } 3\end{array}$} & \multirow{5}{*}{$\begin{array}{l}\text { A one-time inspection } \\
\text { by an expert }\end{array}$} \\
\hline & & 4 & Design code level 4 & & \\
\hline & & 3 & Design code level 3 & & \\
\hline & & 2 & Design code level 2 & & \\
\hline & & 1 & Design code level 1 & & \\
\hline & \multirow[t]{5}{*}{ Condition state of bridge } & 5 & Like new & \multirow{5}{*}{$\begin{array}{l}\text { Legal requirement: } 2 \\
\text { Agreed-on target: } 3\end{array}$} & \multirow{5}{*}{$\begin{array}{l}\text { A yearly inspection by an } \\
\text { external expert }\end{array}$} \\
\hline & & 4 & Slightly deteriorated & & \\
\hline & & 3 & Average & & \\
\hline & & 2 & Poor & & \\
\hline & & 1 & Alarming & & \\
\hline \multirow[t]{5}{*}{ Organisation } & \multirow[t]{4}{*}{ Frequency of monitoring } & 4 & $\begin{array}{l}\text { Regular frequent } \\
\text { monitoring }\end{array}$ & \multirow[t]{4}{*}{ Agreed-on target: 4} & \multirow[t]{4}{*}{$\begin{array}{l}\text { An external audit } \\
\text { every } 5 \text { years }\end{array}$} \\
\hline & & 3 & $\begin{array}{l}\text { Regular but infrequent } \\
\text { monitoring }\end{array}$ & & \\
\hline & & 2 & Irregular monitoring & & \\
\hline & & 1 & No monitoring & & \\
\hline & Quality of emergency plan & 3 & Bridge-specific plan & $\begin{array}{l}\text { Legal requirement: } 2 \\
\text { Agreed-on target: } 3\end{array}$ & $\begin{array}{l}\text { An external audit } \\
\text { every } 5 \text { years }\end{array}$ \\
\hline
\end{tabular}


until the amount of travel time incurred by the users should be restored to normal. The types of targets should be selected for all the restoration intervention costs (i.e. economic costs) and measures of service that stakeholders consider important (i.e. including social, environmental and economic measures of service). In selecting the possible types of targets, the effort required to develop, and evaluate, whether the sets of targets have been achieved should be considered. For example, if specific levels of additional travel time reduction over the restoration period is targeted, which is a specific shape of restoration curve for the travel time measure of service, the effort required to estimate the reduction in additional travel time during the restoration period must be considered.

(b) Develop possible sets of targets, keeping in mind the legal restrictions. These sets of targets consist of a combination of one or more targets for one or more types of targets.

(c) Determine the scenarios of how the targets in each target set are to be reached - for example

(i) To ensure that the users of transport infrastructure experience no increase in travel time if a 100-year flood event occurs, a second bridge to design code level 5 will be built.

(ii) To ensure that the current legal requirements are met, the existing bridge will be strengthened.

(iii) To ensure that restoration intervention costs remain within a specified budget, the existing bridge will be strengthened in a way that makes it easy to rehabilitate following the occurrence of a natural hazard.

(iv) If it is realised during the determination of how the target sets could be achieved, that achieving a target set is not possible - for example, there is not enough money for the second bridge - it should be excluded from further consideration. (d) Estimate the costs of achieving the targets sets and the benefits of each scenario in terms of the restoration intervention costs and measures of service. This requires estimating how the modified transport system will behave following the hazard event. This is done using a combination of available data, expert opinion, models and simulations. It is advised to use ranges of values for all uncertain variables or time estimates to be able to calculate the net present value of the costs, keeping in mind that appropriate discount factors should be used.

For example, achieving a target set might require adding a second bridge, designed according to code level 5, to the transport infrastructure in the previous example, that might cost between $€ 10500000$ (low estimate), $€ 13000000$ (medium estimate) or $€ 16500000$ (high estimate). It might, however, yield benefits in terms of the reduction in restoration intervention costs and the measure of service travel time, which are needed due to the state of the object after the event. For example, the costs of restoring the bridge could be reduced by $€ 150000$ (low estimate), $€ 160000$ (medium estimate) or $€ 170000$ (high estimate), and the additional travel time costs incurred during the restoration period could be reduced by $€ 28000000$ (low estimate), $€ 31000000$ (medium estimate) or $€ 34000000$ (high estimate). Table 19 contains, for this and other two example target sets, examples of ranges of costs to achieve targets, restoration intervention costs and effects on the travel time measure of service.

(e) Evaluate the ability of each scenario to achieve the target sets taking into account the legal requirements and select the best one with respect to the benefits and costs. To do this, the costs of achieving the target sets are compared with their benefits, in terms of the reduction in restoration intervention costs and the effects on the measures of service for which targets are set. The level of precision of the estimates can vary depending on the

Table 19. Expected costs of achievement of target set, effects on restoration intervention costs and effect on the travel time measure of service

\begin{tabular}{|c|c|c|c|c|}
\hline \multirow[b]{2}{*}{ Costs/measure of service } & \multirow[b]{2}{*}{ Estimate } & \multicolumn{3}{|c|}{ Costs and benefits of the target sets: $€$} \\
\hline & & $\begin{array}{c}\text { Target set } 1 \\
\text { 'No changes in } \\
\text { service' }\end{array}$ & $\begin{array}{c}\text { Target set } 2 \\
\text { 'Legal } \\
\text { minimum' }\end{array}$ & $\begin{array}{c}\text { Target set } 3 \\
\text { 'Restoration } \\
\text { budget' }\end{array}$ \\
\hline \multirow[t]{3}{*}{ Costs of achievement of target set } & Low & 10500000 & 9600 & 20000 \\
\hline & Medium & 13000000 & 9600 & 30000 \\
\hline & High & 16500000 & 9600 & 40000 \\
\hline \multirow{3}{*}{$\begin{array}{l}\text { Benefit in terms of reduction in restoration } \\
\text { intervention costs }\end{array}$} & Low & 150000 & 17000 & 12000 \\
\hline & Medium & 160000 & 18000 & 13000 \\
\hline & High & 170000 & 19000 & 14000 \\
\hline \multirow{3}{*}{$\begin{array}{l}\text { Benefit in terms of reduction in additional travel } \\
\text { time costs }\end{array}$} & Low & 28000000 & 17550 & 95400 \\
\hline & Medium & 31000000 & 19500 & 106000 \\
\hline & High & 34000000 & 21450 & 116600 \\
\hline \multirow[t]{3}{*}{ Benefit } & Low & 28150000 & 34550 & 34550 \\
\hline & Medium & 31160000 & 37500 & 37500 \\
\hline & High & 31417000 & 40450 & 40450 \\
\hline \multirow{3}{*}{ Net benefit } & Worst (low benefits - high costs) & 11650000 & 30850 & 67400 \\
\hline & $\begin{array}{l}\text { Medium (medium benefits - } \\
\text { medium costs }\end{array}$ & 18160000 & 27900 & 89000 \\
\hline & Best (high benefits - low costs) & 23670000 & 24950 & 110600 \\
\hline
\end{tabular}


sophistication of the analysis. Three simple examples of how this works are shown in Table 19. The bottom row shows the net benefit for the three target sets, divided into worst, medium and best cases. For target set 1 - for example:

- the worst net benefit is $€ 11650000=(€ 28000000+$ $€ 150000)-€ 16500000$

- the medium net benefit is $€ 18160000=(€ 31000000+$ $€ 160000)-€ 13000000$

ne best net benefit is $€ 23670000=(€ 31417000+$ $€ 170000)-€ 10500000$.

STEP 4.3: RESILIENCE INDICATOR TARGETS WITHOUT COST-BENEFIT ANALYSIS Setting resilience indicator targets without cost-benefit analysis can be summarised as collecting all necessary expert opinions to formulate a broadly accepted set of resilience indicator targets, including the interdependencies between resilience indicators. The targets are formulated so that it is clear how they are to be measured.

In this method, the resilience indicator targets are set, taking into consideration the requirements defined in the previous two steps and by using resilience indicators without the cost-benefit analysis. The previously defined requirements set limits on possible targets - that is, due to some of the requirements, some targets may not be possible. Setting targets requires the opinion of domain experts and the involved stakeholders. As this is often a highly iterative task, sufficient time should be planned to reach a widely supported agreement.

The targets should be set, or consciously not set, for

- each resilience indicator

- each combination of resilience indicators.

In setting the targets, the interdependencies between the indicators should be considered - for example, one might agree to have bridges in a moderate condition state if they have a high design resistance, whereas they should be in a good condition state if they have a moderate design resistance. Once the targets are set, it should be determined how they are to be measured. This task should conclude with a set of targets that are broadly accepted by the stakeholders. For example, Table 20 shows a list of consciously included and excluded resilience indicators from the targets for the example transport system from step 4.1, together with a reason for inclusion or exclusion.
Once the targets to be included are set, it should be determined how they are to be measured. An example of targets and methods of measurements are shown in Table 21, for one earthquake event within 3 years - that is, the targets should be met for one single earthquake and another happening 4 years later but need not to be met if the second earthquake happens 2 years after the first. This task should conclude with a set of targets that are broadly accepted by the stakeholders.

\section{STEP 4.4: RESILIENCE INDICATOR TARGETS WITH COST-BENEFIT ANALYSIS}

Setting resilience indicator targets with cost-benefit analysis can be summarised as a process that takes the level of an indicator first to the legal minimum and then incrementally upgrades the level step by step upwards to the maximum level, if the benefit/ cost ratio of the specific upgrade step is larger than 1.0. This also results in the indicator target with the highest net benefit. The costs considered in this operation are the economic expenditures required to improve an indicator of one level, and the benefits are the reduction in the (social, environmental and economic) impacts on the services due to the improvement of the indicator of one level. In this method, the resilience indicator targets are set, taking into consideration the requirements defined in the previous two tasks and based on the assumption that the net benefit should be maximised. It is similar to that described in step 4.3, with the exception that the costs of achieving the targets are explicitly evaluated regarding the benefits of reaching the targets. The targets should be set, or consciously not set, for

- each resilience indicator

- each combination of resilience indicators.

The method is based on an incremental benefit/cost ratio calculation that investigates the benefit/cost ratio of increasing the indicator target by one level. Choosing the highest indicator target with a positive benefit/cost ratio yields the indicator target with the highest overall net benefit. The sub-tasks required to set targets when reflecting on the costs and benefits of changing indicator values are as follows.

(a) Select the resilience indicators for which targets are to be set for example, the emergency plan resilience indicator.

(b) Each target is set to the lowest value possible - for example, the emergency plan indicator should have a value of 2 (meaning e.g. that the emergency plan is practised every 2 years) if according to law it has to be 2 .

Table 20. Example included and excluded target indicators

\begin{tabular}{llll}
\hline Part & \multicolumn{1}{c}{ Indicator } & Decision & \multicolumn{1}{c}{ Reason } \\
\hline Infrastructure & $\begin{array}{l}\text { Design resistance to hazard } \\
\text { Condition state of bridge }\end{array}$ & Include & Legal requirement present \\
& Seismic zone & Include & Legal requirement present \\
Environment & Regulatory framework & Oxclude & Outside the sphere of influence of the infrastructure operator \\
& Frequency of monitoring & Include & Increases awareness of problems \\
Organisation & Quality of emergency plan & Include & Legal requirement present
\end{tabular}


Table 21. Example service and resilience targets for an earthquake event

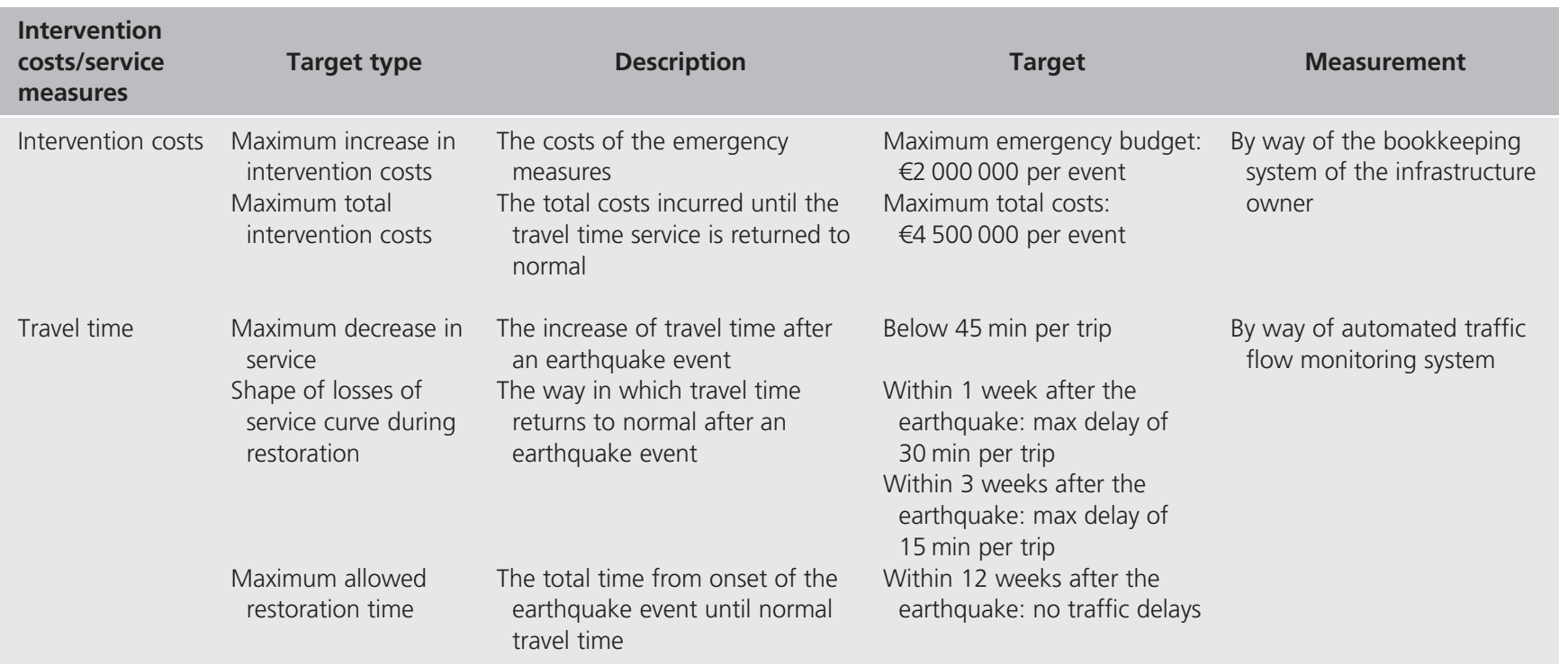

(c) Estimate the additional costs of each unit increase in the value of each indicator from the lowest legally allowed value - for example, the additional costs of increasing the emergency plan indicator from

(i) 2 to 3 - that is, practising the emergency plan every year instead of every 2 years - are $€ 0.8$ million due to the higher number of hours spent on practising

(ii) 3 to 4 - that is, practising the emergency plan every 6 months instead of every year - are $€ 2.0$ million due to the even higher number of hours spent on practising that requires extra personnel to be hired to coordinate and fill in the missing hours in normal work.

(d) Estimate the additional benefits of each unit increase in the value of each indicator from the lowest legally allowed value - for example, the additional benefits of increasing the emergency plan indicator, due to increases in the probability that all organisations involved in emergency actions will act as expected leading to reduced restoration times, from

(i) 2 to 3 are $€ 1.9$ million due to less travel time costs, as the restoration time is shorter (ii) 3 to 4 are $€ 1.95$ million due to even less travel time costs, as the restoration time is now as fast as possible.

(e) Estimate the benefit/cost ratio for each unit increase for each indicator to determine if each increase is worthwhile - for example, the benefit/cost ratio from

(i) 2 to 3 is $1.9 / 0.8=2.375$, which is greater than 1 , meaning that it is worthwhile to increase the value of the emergency plan indicator from 2 to 3

(ii) 3 to 4 is $1.95 / 2.0=0.975$, which is less than 1 , meaning that it is not worthwhile to increase the value of the emergency plan indicator from 3 to 4 .

(f) Set targets for all indicators based on the estimated benefit/ cost ratios, the available resources and the opinions of the stakeholders, which should be able to broadly support the targets - for example, the target for the emergency plan indicator is 3 .

Considering the example transport system from step 4.1, targets for the resilience indicators 'condition state of object' and 'frequency of monitoring' are defined as shown in Table 22. For illustrative

Table 22. Costs and effects on service of increases in the values of two resilience indicators

\begin{tabular}{|c|c|c|c|c|c|c|}
\hline Indicator & Legal req. & Possible values & Increment costs: $€$ & Increment benefit: $€$ & Benefit/cost ratio & Net benefit: $€$ \\
\hline \multirow[t]{5}{*}{ Condition state of object } & - & 1 & - & - & - & - \\
\hline & & 2 & 8000 & 12913 & 1.61 & 4913 \\
\hline & & 3 & 10000 & 10505 & 1.05 & 5418 \\
\hline & & 4 & 11000 & 11121 & 1.01 & 5539 \\
\hline & & 5 & 12000 & 9900 & 0.83 & 3439 \\
\hline \multirow[t]{4}{*}{ Frequency of monitoring } & 2 & 1 & - & - & - & - \\
\hline & & 2 & 10000 & 8800 & 0.88 & -1200 \\
\hline & & 3 & 12000 & 12200 & 1.02 & -1000 \\
\hline & & 4 & 15000 & 10244 & 0.68 & -5756 \\
\hline
\end{tabular}


purposes, along with the legal requirement for the indicators (column 'Legal req.'), the possible values, incremental costs, incremental benefits, benefit/cost ratio and net benefit are shown. The increment costs are due to executing more interventions to keep the condition state better and for more frequent monitoring due to higher monitoring costs. The increment benefits can be due to lower restoration intervention costs and a shorter travel time because of the better state of the object following the event due to the initial condition of the object and faster restoration due to better information because of frequent monitoring. The benefit/cost ratio is due to increasing the value of the indicator by 1 . The last column shows the total net benefit - that is, the sum of the upgrade benefits from indicator level 1 to the respective indicator level minus the sum of the associated upgrade costs. For example, the net benefit for the condition state of object level 3 is $(€ 12913+€ 10505)-(€ 8000+$ $€ 10000)=€ 5418$.

To follow the incremental process, and because it is assumed that there is no legal requirement for the condition state of the object, the incremental process starts at level 1 and, with a benefit/cost ratio of 1.61 , is moved to level 2 as a target. As the benefit/cost ratio for moving from level 2 to level 3 is 1.05 , the target is further moved to level 3 . Even more, as the benefit/cost ratio to upgrade from level 3 to level 4 is 1.01 , and thus larger than 1.0 (but barely), the target is moved to level 4 . The move from level 4 to level 5, however, is not done with the benefit/cost ratio being 0.83 and thus smaller than 1 . This signifies that for every extra euro spent, there is only a return of $€ 0.83$. Therefore, the target should stay at level 4. The associated net benefit, which is the highest, is $€ 5539$. For the indicator 'frequency of monitoring', the process starts at level 2, which is the legal requirement. The benefit/cost ratio to upgrade to level 3 is 1.02 , and so the target is moved to level 3. As the further upgrade from level 3 to level 4 has a benefit/cost ratio of 0.68 , the target stays at level 3 . The associated net benefit, which is the highest but still negative, is$€ 1000$. With this, the target for the indicators should be set to level 4 of 5 for the indicator 'condition state of object' and level 3 of 4 for the indicator 'frequency of monitoring'.

\section{Conclusions}

The guideline presented is to be used to determine how to measure, and set targets for, the service provided by, and the resilience of, transport infrastructure. It includes concepts of service and resilience and how they are linked, which enables both service and resilience to be measured and target for these to be set. The way to measure service and resilience and set targets presented here is suitable for a range of investigations from detailed model-based investigations, using simulations with extensive modelling effort to general expert opinion-based investigations, to indicator-based investigations to a less detailed investigation based only on the percentage of fulfilment of the resilience. To use this guideline to determine how to measure, and set targets for, service and resilience, it is important to have a clear objective to do so - for example, to determine the areas of a specific transport system or a specific part of a transport system to improve resilience or to make comparisons between transport systems or parts of transport systems.

For demonstration, in this paper, the explanation of the steps of the guideline has been supported by their use on an example transport system. The example is meant to show how the guideline can be used in practice, with relatively little inputs and effort to $(a)$ obtain an indicative measure service and resilience provided and $(b)$ estimate the targets for resilience - that is, how much should infrastructure managers invest to improve the resilience of their transport systems.

The authors acknowledge that following this paper, further work is required to use the guideline to measure the service and resilience on a real case study and to validate the measure of resilience done with the indicators, against that obtained directly through simulations to verify reliability of results.

\section{Acknowledgements}

This work has received funding from the EU Horizon 2020 research and innovation programme under the grant agreement 769373 (Foresee project). The authors wish to acknowledge the precious support of the project partners in developing the guideline. In this sense, a special sense of gratitude goes to the case studies leaders: Livia Pardi from Autostrade per l'Italia, Federico di Gennaro from the Italian Association of Toll Motorways and Tunnels Concessionaire Companies, Antonia Perez from the Universidad de Cantabria, Christoph Schütze from Ingenieurgesellschaft für Verkehrs- und Eisenbahnwesen mbH, David Delgado Zaldívar from Ferrovial Agroman and André Martinez Gonzalez de Oliveira e Costa and Maria Leonor Martins do Nascimento from Infraestruturas de Portugal sa. A particular acknowledgement is also due to Jesús Rodríguez and all the members of the Foresee Stakeholders' Reference Group that have provided precious feedbacks to improve the first versions of the guidelines. Despite the support received, this paper reflects only the author's views. The European Commission and Innovation and Networks Executive Agency are not responsible for any use that may be made of the information contained therein.

\section{REFERENCES}

Achtnicht M (2012) German car buyers, willingness to pay to reduce $\mathrm{CO}_{2}$ emissions. Climatic Change 113(3-4): 679-697, https://doi.org/10. 1007/s10584-011-0362-8.

Adey BT, Herrmann T, Tsafatinos K et al. (2010) Methodology and base cost models to determine the total benefits of preservation interventions on road sections in Switzerland. Structure and Infrastructure Engineering: Maintenance, Management, Life-cycle Design and Performance 8: 639-654, https://doi.org/10.1080/ 15732479.2010.491119.

Adey BT, Lethanh N and Lepert P (2012) An impact hierarchy for the evaluation of intervention strategies for public roads. Proceedings of the 4th European Pavement and Asset Management Conference (EPAM 2012), Malmö, Sweden.

Adey BT, Hackl J, Lam JC et al. (2016) Ensuring acceptable levels of infrastructure related risks due to natural hazards with emphasis on stress tests. Proceedings of the 1st International Symposium on Infrastructure Asset Management (SIAM), Kyoto, Japan. 
Adey BT, Martani C, Kielhauser C et al. (2019) FORESEE Project: Deliverable D1.1 - Guideline to Measure Service Provided by, and Resilience of, Transport Infrastructure. Foresee Project, Brussels, Belgium.

Adey BT, Burkhalter M and Martani C (2020) Defining road service to facilitate road infrastructure asset management. Infrastructure Asset Management 7(4): 240-255, https://doi.org/10.1680/jinam.18.00045.

Asam S, Bhat C, Dix B et al. (2015) Climate Change Adaptation Guide for Transportation Systems Management, Operations, and Maintenance. FHWA-HOP-15-026.

Aydin N (2017) A fuzzy-based multi-dimensional and multi-period service quality evaluation outline for rail transit systems. Transport Policy 55: 87-98, https://doi.org/10.1016/j.tranpol.2017.02.001.

Bickel P and Friedrich R (eds) (2005) ExternE: Externalities of Energy Methodology 2005 Update. Office for Official Publications of the European Communities, Luxemburg, Luxemburg.

Brown R, Smith B and Curley J (2014) Transport Resilience Review: A Review of the Resilience of the Transport Network to Extreme Weather Events. Her Majesty's Stationery Office, London, UK.

Caetano LF and Teixeira PF (2013) Availability approach to optimizing railway track renewal operations. Journal of Transportation Engineering 139(9): 941-948, https://doi.org/10.1061/(ASCE)TE. 1943-5436.0000575.

Caliendo C and De Guglielmo ML (2012) Accident rates in road tunnels and social cost evaluation. Procedia - Social and Behavioral Sciences 53: 166-177, https://doi.org/10.1016/j.sbspro.2012.09.870.

Cascetta E, Papola A, Pagliara F and Marzano V (2011) Analysis of mobility impacts of the high speed Rome-Naples rail link using within day dynamic mode service choice models. Journal of Transport Geography 19(4): 635-643, https://doi.org/10.1016/j.jtrangeo.2010.07. 001.

Cavana RY, Corbett LM and Lo YL (2007) Developing zones of tolerance for managing passenger rail service quality. International Journal of Quality \& Reliability Management 24(1): 7-31, https://doi.org/10. 1108/02656710710720303.

Chou PF, Lu CS and Chang YH (2014) Effects of service quality and customer satisfaction on customer loyalty in high-speed rail services in Taiwan. Transportmetrica A: Transport Science 10(10): 917-945, https://doi.org/10.1080/23249935.2014.915247.

de Blaeij A, Florax RJGM, Rietveld P and Verhoef E (2003) The value of statistical life in road safety: a meta-analysis. Accident Analysis \& Prevention 35(6): 973-986, https://doi.org/10.1016/S0001-4575(02) 00105-7.

de Oña J, de Oña R, Eboli L and Mazzulla G (2015) Heterogeneity in perceptions of service quality among groups of railway passengers. International Journal of Sustainable Transportation 9(8): 612-626, https://doi.org/10.1080/15568318.2013.849318.

Dykes AL (2018) The Car Interior Noise Level Comparison. Paris, France.

Eboli L and Mazzulla G (2012) Structural equation modelling for analysing passengers, perceptions about railway services. ProcediaSocial and Behavioral Sciences 54: 96-106, https://doi.org/10.1016/j. sbspro.2012.09.729.

Ecoplan (2010) Sustainability indicators for road infrastructure projects. In Handbuch eNISTRA (Ecoplan (ed.)). Ecoplan, Bern, Switzerland.

Elvik R (2000) How much do road accidents cost the national economy? Accident Analysis \& Prevention 32(6): 849-851, https://doi.org/10. 1016/S0001-4575(00)00015-4.

FHWA (Federal Highway Administration) (2002) Managing Bridges the Pontis Way. FHWA, Washington, DC, USA, No. FHWA-RD-02-012.

Figueiredo L, Honiden T and Schumann A (2018) Indicators for Resilient Cities. OECD Publishing, Paris, France.

Hackl J, Adey BT and Lethanh N (2018a) Determination of near-optimal restoration programs for transportation networks following natural hazard events using simulated annealing. Journal of Computer-aided Civil and Infrastructure Engineering 33: 618-637.
Hackl J, Lam JC, Heitzler M, Adey BT and Hurni L (2018b) Estimating network related risks: a methodology and an application for roads. Natural Hazards and Earth System Sciences 18: 2273-2293, https:// doi.org/10.5194/nhess-18-2273-2018.

Hughes JF and Healy K (2014) Measuring the Resilience of Transport Infrastructure. NZ Transport Agency, Wellington, New Zealand, Research Report 546.

Ihs A (2004) The influence of road surface condition on traffic safety and ride comfort. Proceedings of the 6th International Conference on Managing Pavements: The Lessons, the Challenges, the Way Ahead, Brisbane, Queensland, pp. 11-21.

ISO (International Organization for Standardization) (2018) ISO 37120:2018: Sustainable cities and communities - indicators for city services and quality of life infrastructure protection. Part II: A new approach. ISO, Geneva, Switzerland.

Jha AK, Miner TW and Stanton-Geddes Z (eds) (2013) Building Urban Resilience: Principles, Tools, and Practice. World Bank, Washington, DC, USA.

Jou RC, Chien JY and Wu YC (2013) A study of passengers, willingness to pay for business class seats of high-speed rail in Taiwan.

Transportmetrica A: Transport Science 9(3): 223-238, https://doi.org/ 10.1080/18128602.2011.565816

Kasnatscheew A, Hein F, Schoenebeck S, Lerner M and Hosta P (2016) Review of European Accident Cost Calculation Methods - With Regard to Vulnerable Road Users. InDeV Project, Bergisch Gladbach, Germany, Deliverable 5.1.

Keeney RL and Raiffa H (1993) Decisions with Multiple Objectives: Preferences and Value Trade-offs. Cambridge University Press, Cambridge, UK.

Kielhauser C, Martani C and Adey BT (2019) Guideline to Set Target Levels of Service and Resilience for Infrastructures. Foresee EU Project, Brussels, Belgium.

Korzhenevych A, Dehnen N, Bröcker J et al. (2014) Update of the Handbook on External Costs of Transport. Final Report. RicardoAEA, London, UK.

Kumares CS and Samuel L (2007) Transportation Decision Making: Principles of Project Evaluation and Programming. Wiley, New York, NY, USA.

Lam JC, Adey BT, Heitzler M et al. (2018) Stress tests for a road network using fragility functions and functional capacity loss functions. Reliability Engineering \& System Safety 173: 78-93, https://doi.org/ 10.1016/j.ress.2018.01.015.

Layard PRG (1994) Cost-Benefit Analysis. Cambridge University Press, Cambridge, UK.

Maibach M, Schreyer C, Sutter D et al. (2008) Handbook on Estimation of External Costs in the Transport Sector: Produced within Internalisation Measures and Policies for All External Cost of Transport (IMPACT), version 1.1. CE Delft, Delft, the Netherlands.

Milligan C, Kopp A, Dahdah S and Montufar J (2014) Value of a statistical life in road safety: a benefit-transfer function with riskanalysis guidance based on developing country data. Accident Analysis \& Prevention 71: 236-247, https://doi.org/10.1016/j.aap.2014.05.026.

Nathanail E (2008) Measuring the quality of service for passengers on the hellenic railways. Transportation Research Part A: Policy and Practice 42(1): 48-66, https://doi.org/10.1016/j.tra.2007.06.006.

Neetesh S, Armin T and Gardoni P (2018) Resilience analysis: a mathematical formulation to model resilience of engineering systems. Sustainable and Resilient Infrastructure 3(2): 49-67, https://doi.org/ 10.1080/23789689.2017.1345257.

NZTA (New Zealand Transport Agency) (2010) Economic Evaluation Manual. NZTA, Wellington, New Zealand.

OECD (Organisation for Economic Co-operation and Development) (2018) Passenger Transport (Indicator). OECD, Paris, France.

Papathanasiou N, Adey BT and Burkhalter M (2020) Defining and quantifying railway service to plan infrastructure interventions. 
Infrastructure Asset Management

Volume 8 Issue 4
Estimating, and setting targets for, the

resilience of transport infrastructure

Adey, Martani, Kielhauser et al.
Infrastructure Asset Management 7(3): 146-166, https://doi.org/10. 1680/jinam.18.00044.

Patra AP, Kumar U and Kråik POL (2010) Availability target of the railway infrastructure: an analysis. 2010 Proceedings - Annual Reliability and Maintainability Symposium (RAMS), San Jose, CA, USA, pp. 1-6.

Pearce D, Atkinson G and Mourato S (2006) Cost-Benefit Analysis and the Environment: Recent Developments. OECD, Paris, France.

Prior T (2015) Measuring Critical Infrastructure Resilience: Possible Indicators. Risk and Resilience Research Group, Center for Security Studies, ETH Zurich, Zurich, Switzerland.

Stenström C, Parida A and Kumar U (2016) Measuring and monitoring operational availability of rail infrastructure. Proceedings of the Institution of Mechanical Engineers, Part F: Journal of Rail and Rapid Transit 230(5): 1457-1468, https://doi.org/10.1177/ 0954409715592189.

Stipanovic I, Chatzi E, Limongelli M et al. (2017) WG2 Technical Report: Performance Goals for Roadway Bridges of COST ACTION TU 1406. Boutik, Braga, Portugal.

Theocharidou M and Giannopoulos G (2015) Risk Assessment Methodologies for Critical Infrastructure Protection. Part II: A New Approach. Publications Office of the EU, Luxemburg, Luxemburg.
Tingvall C, Stigson H, Eriksson L et al. (2010) The properties of Safety Performance Indicators in target setting, projections and safety design of the road transport system. Accident Analysis \& Prevention 42(2): $372-376$.

USDOT (US Department of Transportation) (2015) Vulnerability Assessment Scoring Tool, User's Guide. USDOT, Washington, DC, USA.

van Oort N and van Nes R (2010) Impact of rail terminal design on transit service reliability. Transportation Research Record 2146(1): 109-118, https://doi.org/10.3141/2146-14.

VSS (Schweizerischer Verband der Strassen- und Verkehrsfachleute) (2009a) SN 641 822a: Cost benefit analysis for road traffic: travel time costs for passenger traffic. VSS, Zurich, Switzerland.

VSS (2009b) SN 641 828: Cost benefit analysis for road traffic: external costs. VSS, Zurich, Switzerland.

VSS (2013) SN 641 824: Cost benefit analysis for road traffic: accidents and accident cost rates. VSS, Zurich, Switzerland.

Wüthrich P, Notter B, Althous H-J and Graf C (2017) Luftschadstoffemissionen des Strassenverkehrs der Schweiz. Bern, Switzerland.

Zalbide M, Garcia-Sanchez D, Aurtenetxe J et al. (2018) RAGTIME Risk based approaches for Asset inteGrity multimodal Transport Infrastructure. Proceedings of TRA 2018, Vienna, Austria.

\section{How can you contribute?}

To discuss this paper, please submit up to 500 words to the editor at journals@ice.org.uk. Your contribution will be forwarded to the author(s) for a reply and, if considered appropriate by the editorial board, it will be published as a discussion in a future issue of the journal. 